\title{
Mass Flow Rate and Isolation Characteristics of Injectors for Use with Self-Pressurizing Oxidizers in Hybrid Rockets
}

\author{
Benjamin S. Waxman*, Jonah E. Zimmerman ${ }^{\dagger}$, Brian J. Cantwell ${ }^{\ddagger}$ \\ Stanford University, Stanford, CA 94305 \\ and \\ Gregory G. Zilliac ${ }^{\S}$ \\ NASA Ames Research Center, Moffet Field, CA 94035
}

\begin{abstract}
Self-pressurizing rocket propellants are currently gaining popularity in the propulsion community, particularly in hybrid rocket applications. Due to their high vapor pressure, these propellants can be driven out of a storage tank without the need for complicated pressurization systems or turbopumps, greatly minimizing the overall system complexity and mass. Nitrous oxide $\left(\mathrm{N}_{2} \mathrm{O}\right)$ is the most commonly used self pressurizing oxidizer in hybrid rockets because it has a vapor pressure of approximately $730 \mathrm{psi}(5.03 \mathrm{MPa})$ at room temperature and is highly storable. However, it can be difficult to model the feed system with these propellants due to the presence of two-phase flow, especially in the injector. An experimental test apparatus was developed in order to study the performance of nitrous oxide injectors over a wide range of operating conditions. Mass flow rate characterization has been performed to determine the effects of injector geometry and propellant sub-cooling (pressurization). It has been shown that rounded and chamfered inlets provide nearly identical mass flow rate improvement in comparison to square edged orifices. A particular emphasis has been placed on identifying the critical flow regime, where the flow rate is independent of backpressure (similar to choking). For a simple orifice style injector, it has been demonstrated that critical flow occurs when the downstream pressure falls sufficiently below the vapor pressure, ensuring bulk vapor formation within the injector element. It has been proposed to leverage the insensitivity of critical mass flow rate to downstream pressure as a means of preventing the occurrence of feed system coupled combustion instabilities in hybrid rockets utilizing nitrous oxide. Additionally, observations indicate that the existence of two-phase flow can attenuate pressure fluctuations traveling upstream through the injector, providing a degree of isolation between the feed line and downstream pressure disturbances. In consideration of safety, carbon dioxide $\left(\mathrm{CO}_{2}\right)$ has been used as an analog to nitrous oxide in many of these studies. It has been observed experimentally that carbon dioxide serves as a good analog to nitrous oxide in both the single-phase and two-phase flow regimes.
\end{abstract}

\section{Nomenclature}

$\begin{aligned} A & =\text { injector hole cross-sectional area } \\ C_{d} & =\text { discharge coefficient } \\ D & =\text { injector hole diameter } \\ h & =\text { specific enthalpy } \\ L & =\text { injector hole length } \\ \dot{m} & =\text { mass flow rate } \\ P & =\text { pressure } \\ Q & =\text { volumetric flow rate } \\ s & =\text { specific entropy } \\ t & =\text { time } \\ T & =\text { temperature } \\ u & =\text { fluid velocity } \\ Z & =\text { compressibility factor }\end{aligned}$

$\begin{array}{lll}\text { Subscripts } & \\ 1 & =\text { location upstream of injector } \\ 2 & = & \text { location downstream of injector } \\ b & = & \text { bubble growth } \\ c & = & \text { thermodynamic critical conditions } \\ \text { crit } & =\text { critical flow } \\ l & =\text { liquid } \\ r & =\text { residence within injector } \\ \text { s } & =\text { saturation } \\ \text { super } & =\text { supercharge } \\ \text { trip } & =\text { thermodynamic triple point } \\ v & = & \text { vapor }\end{array}$

*Graduate Student, SPaSE Lab, Department of Aeronautics \& Astronautics, Stanford University, CA, AIAA Student Member.

${ }^{\dagger}$ Graduate Student, SPaSE Lab, Department of Aeronautics \& Astronautics, Stanford University, CA, AIAA Student Member.

${ }^{\ddagger}$ Edward C. Wells Professor, Department of Aeronautics \& Astronautics, Stanford University, CA, AIAA Fellow.

${ }^{\S}$ Research Scientist, NASA Ames Research Center/M.S. 260-1, Moffett Field, CA, AIAA Member. 


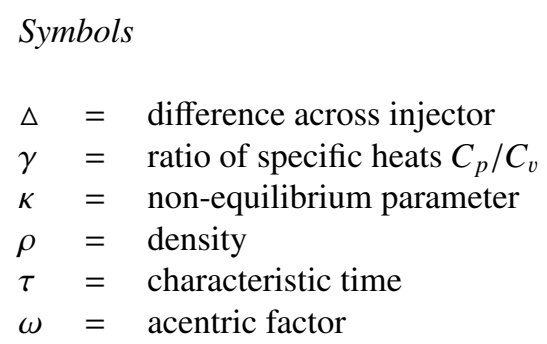

\section{Introduction}

Interest in self-pressurizing rocket propellants is at an all time high, especially in the field of hybrid rocket propulsion. Specifically, nitrous oxide $\left(\mathrm{N}_{2} \mathrm{O}\right)$ has recently seen a surge in popularity as a self-pressurizing liquid oxidizer for use in hybrid rockets, ranging from small scale amateur and academic projects to full scale development programs ${ }^{1,2}$. Nitrous oxide has a vapor pressure (also called saturation pressure, $P_{s}$ ) of approximately $730 \mathrm{psi}(5.03 \mathrm{MPa})$ at room temperature, making it an attractive oxidizer choice for hybrid rockets because it can be expelled from a storage tank without the need for complicated pressurization systems or turbopumps. Additionally, nitrous oxide is highly storable, relatively nontoxic, and easy to handle. Therefore, it is generally considered a safer alternative to the more traditional oxidizers typically used in launch systems today. However, to date, there has been little published data presented in the open literature on nitrous oxide feed systems in hybrid rockets with regard to the design and performance of elements such as propellant tanks, feed lines, valves, and injectors.

Specifically, injector design can have a dramatic effect on the overall efficiency and stability of a hybrid rocket. A properly designed injector should provide the desired oxidizer mass flow rate to the combustion chamber, while sufficiently atomizing the liquid to allow for rapid vaporization of the droplets. Previous work by the authors has studied the atomization process, while the focus of this work involves the characterization of mass flow rate for varying injector designs and operating conditions ${ }^{3}$. Some background of the current methods used to predict mass flow rate through injectors is included, however more detailed information can be found in a previous work by the authors, from which a portion of this work has been reproduced ${ }^{4}$. Next, a description of the experimental test apparatus will be presented, followed by some mass flow rate characterization results. Based on results from these mass flow rate studies, a test campaign has been initiated in order to assess the feasibility of using the injector as a feed system isolating element in a fashion similar to that of a cavitating venturi. The later parts of this work will provide some details on this type of testing, as well as some initial experimental results.

\section{Background Theory}

\section{A. Single-Phase Incompressible Liquid Flow}

Typical rocket propellants such as liquid oxygen, kerosene and liquid hydrogen are often adequately modeled as incompressible liquids. For single-phase incompressible (SPI) fluid flow through an injector orifice, the steady Bernoulli equation results in the well known " $C_{d} A$ " equation for the volumetric flow rate, $Q$, and the mass flow rate, $\dot{m}$, as shown in Eqn. (1).

$$
\dot{m}_{S P I}=Q \rho=C_{d} A \sqrt{\frac{2 \rho \Delta P}{1-\left(\frac{A}{A_{1}}\right)^{2}}}
$$

where $C_{d}$ is the dimensionless discharge coefficient, $\rho$ is the mass density, $A$ is the cross-sectional area of the orifice, and $A_{1}$ is the upstream cross-sectional area. The variable $\Delta P$ is defined as the pressure drop across the injector and is equal to $P_{1}-P_{2}$, where $P_{1}$ is the pressure upstream of the injector and $P_{2}$ is the downstream pressure (also referred to as backpressure or chamber pressure). In many practical cases relating to injectors, $A \ll A_{1}$, and the denominator under the square root in Eqn. (1) approaches unity, resulting in the commonly used form of the " $C_{d} A$ " equation shown in Eqn. (2). Even when $A$ and $A_{1}$ are comparable, the denominator under the square root is often wrapped into $C_{d}$. 


$$
\dot{m}_{S P I}=C_{d} A \sqrt{2 \rho \Delta P}
$$

This is the form of the " $C_{d} A$ " equation typically used for rocket injector design as presented by Sutton and Biblarz ${ }^{5}$, and is the form that the experimental portion of the current work will use when referring to the discharge coefficient (sometimes referred to as the SPI discharge coefficient).

\section{B. Two-Phase Flow}

Most traditional propellants are used as sub-cooled liquids due to their low vapor pressures and typically high operating pressures. Assuming the discharge coefficient is well characterized for a given injector design, the " $C_{d} A$ " equation can be used with a high degree of confidence for these traditional propellants. Unfortunately, this method is often applied inappropriately to injectors of high vapor pressure propellants such as nitrous oxide, with error often introduced by compressibility effects (compressibility factor $Z \sim 0.12$ for saturated liquid, $Z \sim 0.57$ saturated vapor at room temperature ${ }^{6,7}$ ) and the development of two-phase flow within the orifice. The effects of compressibility are usually overshadowed by the introduction of two-phase flow, therefore this work will focus on the latter. A description of modeling the compressibility effects in nitrous oxide injectors is included for convenience in Appendix A.

For self-pressurizing propellants such as nitrous oxide, the operating pressures in the feed system are often very close to the vapor pressure. As a result, local static pressures within the injector can reach values well below the vapor pressure as the liquid accelerates and expands. Under these conditions, cavitation and flash vaporization can occur within the injector orifice, greatly decreasing the bulk fluid density. Figure 1 (adapted from Dyer et al. ${ }^{8}$ ) schematically illustrates the evolution of static pressure throughout an injector for a low vapor pressure propellant in comparison to that of a high vapor pressure propellant.

Figure 1a shows a typical static pressure profile for a low vapor pressure propellant as it passes through an injector. It should be noted that the vena contracta (v.c.) depicted in Figure 1a is caused by flow separation and may or may not contain vapor pockets, depending on the pressure level in the vicinity of the sharp edge. In cases where the bulk static pressure drops below the vapor pressure within the injector as shown in Figure 1b, significant vapor formation will occur, and the mass flow rate will be limited. This effect was demonstrated by the work of Hesson and Peck, in which the mass flow rate of saturated carbon dioxide $\left(\mathrm{CO}_{2}\right)$ flow through simple orifices was studied (orifice length to diameter ratio $L / D \sim 1.7)^{9}$. Similar to nitrous oxide, carbon dioxide is a high vapor pressure liquid at room temperature. In fact, often carbon dioxide is used as an analog to nitrous oxide because the thermodynamic and transport properties of the two are so similar (this will be discussed later in detail). Figure 2 shows mass flux versus downstream pressure, $P_{2}$, for lines of constant upstream pressure $P_{1}$ as presented by Hesson and Peck ${ }^{9}$. This figure shows that for a given upstream pressure, a maximum mass flow rate is achieved as the downstream pressure drops below some critical value, essentially "choking" the orifice with regard to mass flow. This is referred to as critical flow, and in this regime the mass flow rate is independent of the downstream pressure. In order to accurately model the mass flow rate in two-phase injectors, this critical flow phenomenon must be accounted for.

A model that is commonly used to predict the two-phase critical flow rate through an injector orifice is called the Homogeneous Equilibrium Model (HEM). In this model, it is assumed that the liquid and vapor phases are in thermal equilibrium, there is no velocity difference between the phases, and the flow is isentropic across the injector. The critical mass flow rate is calculated by seeking a maximum in the mass flow rate expression derived from the first law of thermodynamics which is shown in Eqn. (3) and by following a line of constant entropy ${ }^{10,11}$.

$$
\begin{gathered}
\dot{m}_{H E M}=C_{d} A \rho_{2} \sqrt{2\left(h_{1}-h_{2}\right)} \\
s_{1}=s_{2}
\end{gathered}
$$



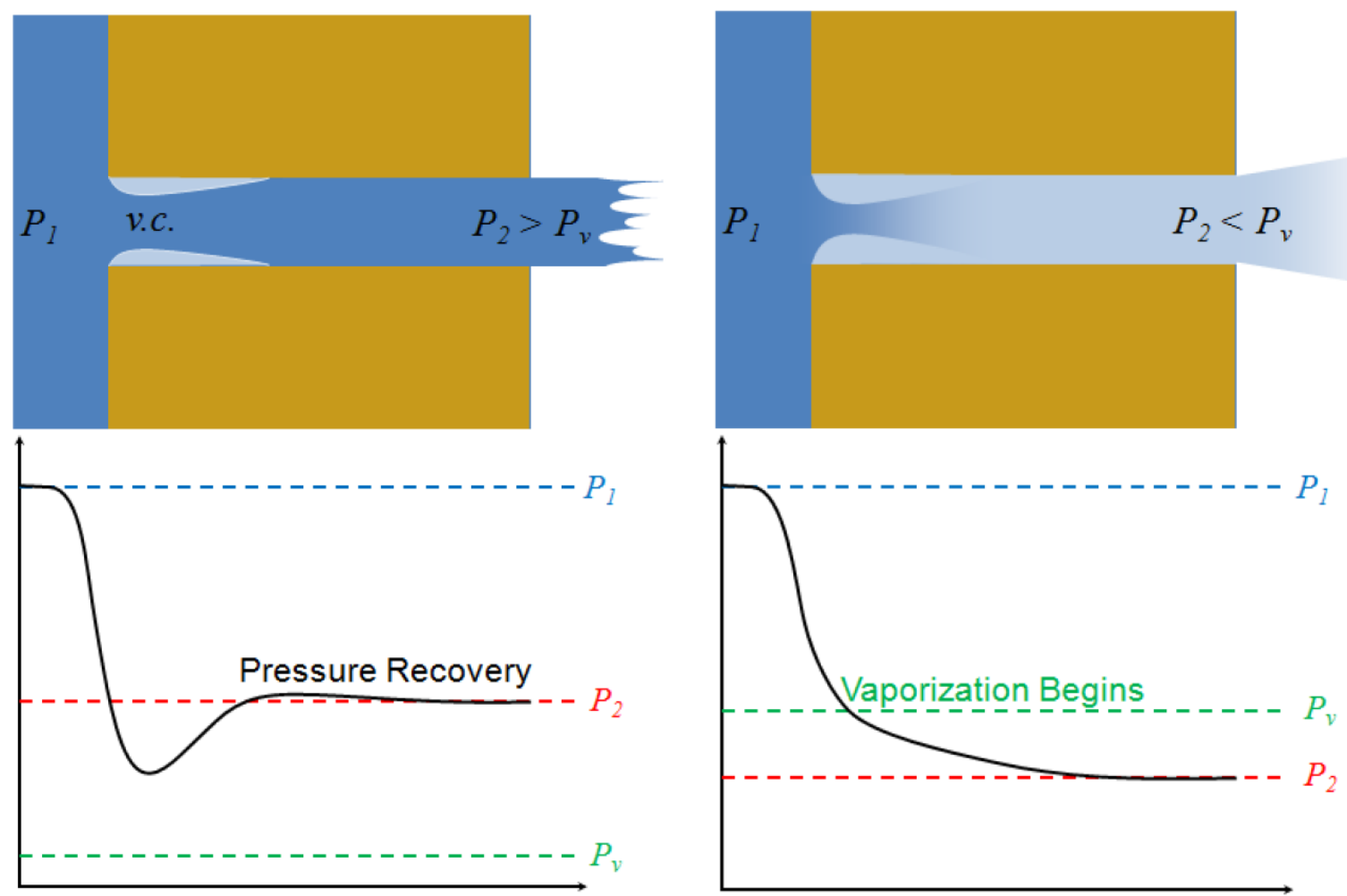

(a)

(b)

Figure 1. Conceptual injector pressure history as adapted from work by Dyer et al. showing (a) low vapor pressure propellant and (b) high vapor pressure propellant with flow from left to right ${ }^{8}$. The minimum area of contraction due to flow separation is denoted by v.c. (vena contracta).

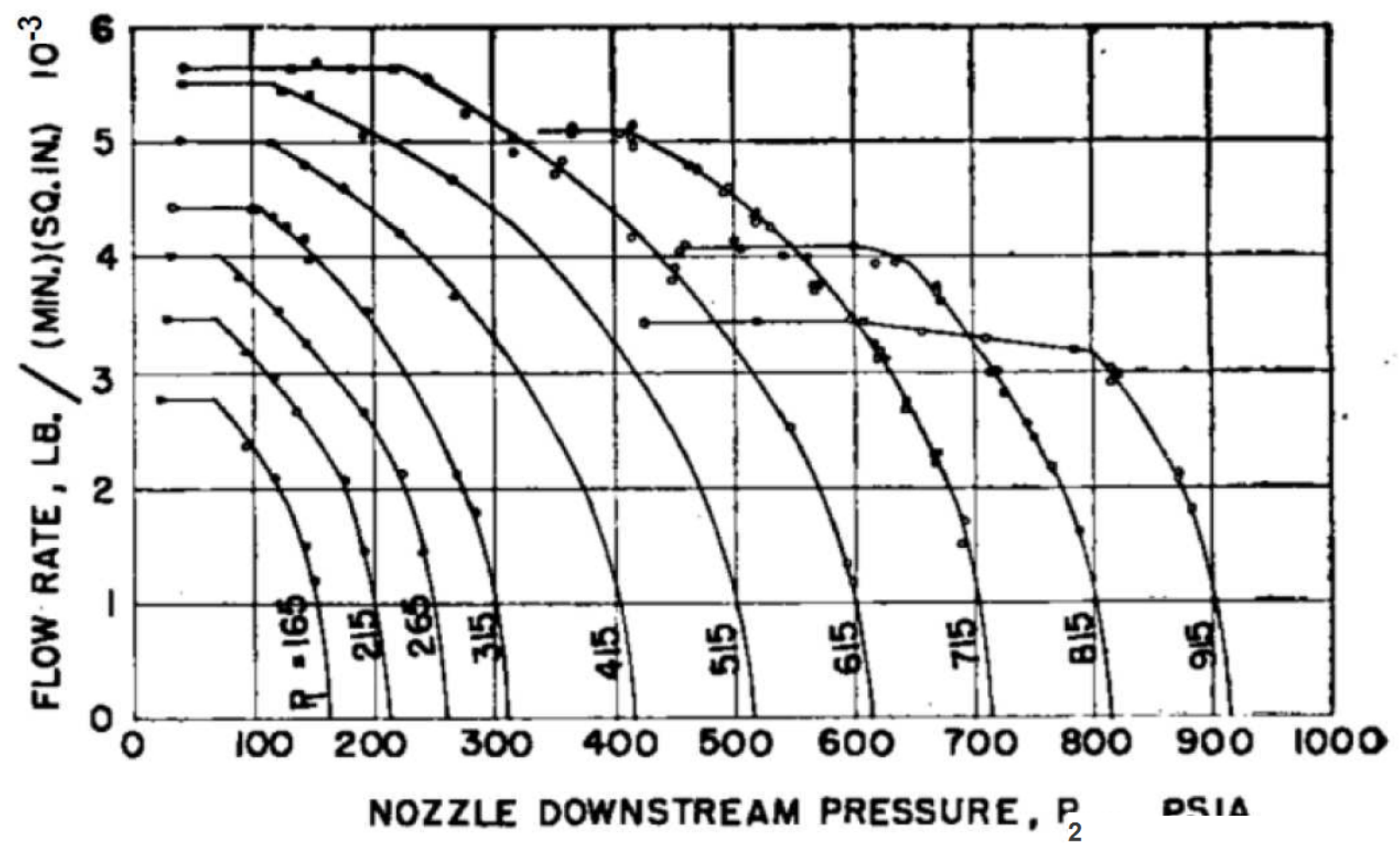

Figure 2. Sample of saturated carbon dioxide flow rate mapping reproduced from Hesson and Peck (orifice length to diameter ratio $L / D \sim$ 1.7) ${ }^{9}$. 
Here, $h_{1}$ is the upstream specific enthalpy, $h_{2}$ is the downstream specific enthalpy, $s_{1}$ is the upstream specific entropy, and $s_{2}$ is the downstream specific entropy. When the upstream temperature and pressure are known, as well as the backpressure, the calculation of mass flow rate for nitrous oxide using the Homogeneous Equilibrium Model is made trivial through the use of highly accurate equations of state programmed in REFPROP ${ }^{6,7}$. At critical flow, the HEM mass flow exhibits a maximum with respect to the downstream pressure as described in Eqn. (5).

$$
\dot{m}_{\text {crit } H E M}=\left.\dot{m}_{H E M}\right|_{\left(\frac{\partial \dot{m}_{H E M}}{\partial P_{2}}=0\right)}
$$

A graphical representation of this type of critical flow calculation is included in Figure 3, which models an injector for initially saturated liquid nitrous oxide at room temperature $(293 \mathrm{~K})$. It is clear from the plot that for downstream pressures below the critical value, the equilibrium model does not level off and remain constant in the same way seen in the experimental data from the work of Hesson and Peck ${ }^{9}$. Therefore while it may be appropriate to use the HEM as a means to predict the mass flow rate up to the critical value (subject to validation), it is not necessarily suitable for calculations of the mass flow rate in general at pressure drops greater than the critical value.

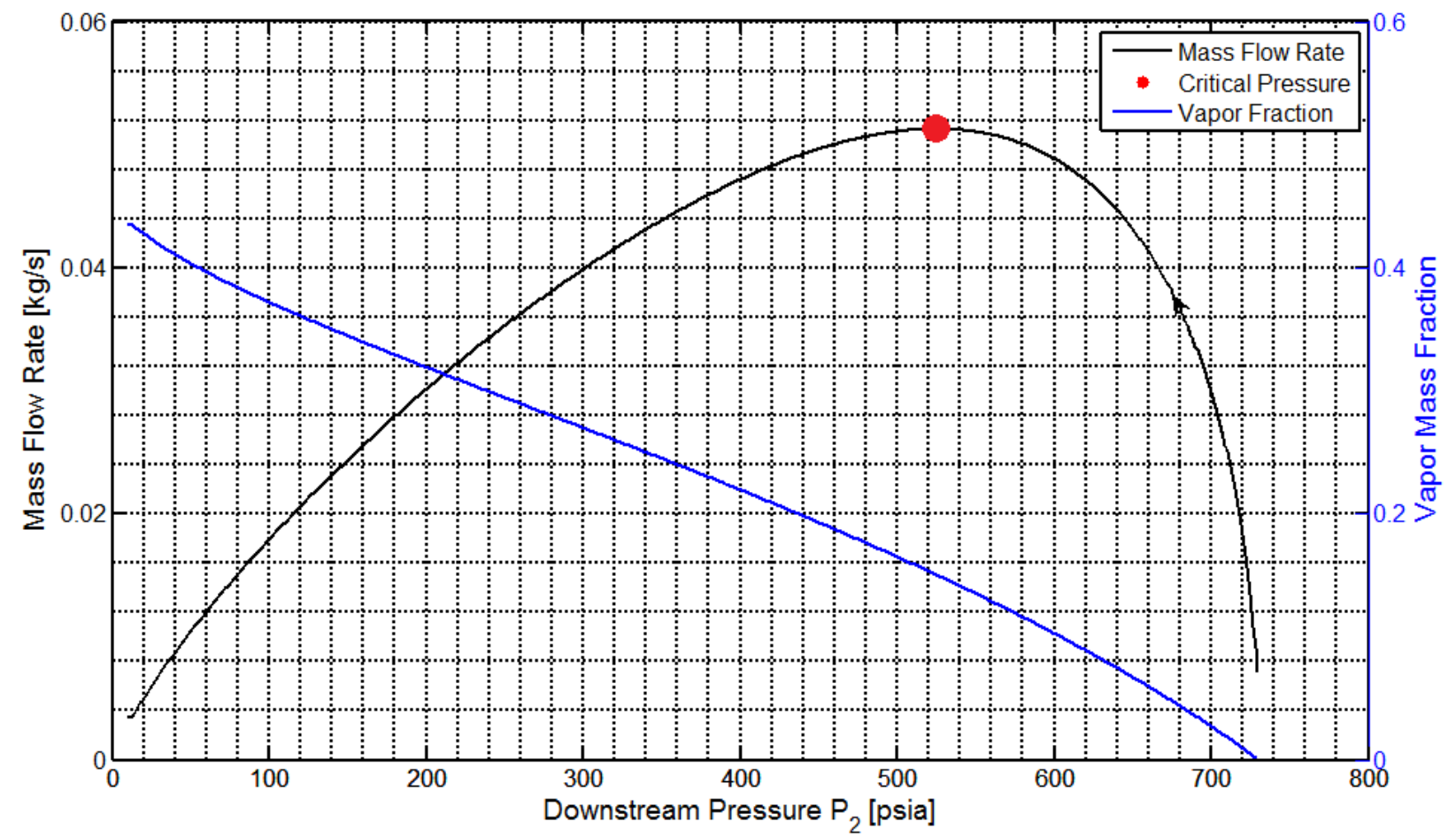

Figure 3. Critical mass flow rate prediction using the Homogeneous Equilibrium Model for initially saturated liquid nitrous oxide at 730 psia (5.03 MPa) corresponding to room temperature $(293 \mathrm{~K})$. The data used to produce this plot was calculated using REFPROP ${ }^{6,7}$.

It is expected that if the assumption of equilibrium is valid, the HEM should do a good job of predicting the critical mass flow rate. However, thermodynamic equilibrium is only a limiting case, and gives a lower-bound estimate for the critical mass flow rate ${ }^{12}$. Furthermore, experimental data suggest that the critical mass flow rate for many short tube injectors is significantly underpredicted using the HEM, likely due to non-equilibrium effects ${ }^{8}$. In fact, as an orifice approaches the thin plate limit, it is likely that no critical flow regime will be observed. 


\section{Two-Phase Flow with Non-Equilibrium Effects}

The equilibrium model described above begins to break down when the finite rate of heat and mass transfer between the liquid and vapor phases prohibits the injector flow from reaching thermodynamic equilibrium. Dyer et al. proposed that non-equilibrium effects were predominantly caused by two processes: superheating of the liquid during expansion and finite vapor bubble growth rates $^{8}$. In hybrid rockets, nitrous oxide can be used as a saturated liquid or a secondary pressurization system is used to sub-cool the liquid in a process called supercharging. In both cases, the static pressure drops as the fluid accelerates and expands through the injector. When the pressure falls below the saturation pressure, vapor formation may initiate almost immediately, especially when nucleation sites are readily available. However, often this is not the case, and instead the liquid enters a metastable state ${ }^{8}$. In this scenario, the nitrous oxide becomes a superheated liquid, at which point very small disturbances or the introduction of nucleation sites can result in local flashing of the liquid to vapor. More information about metastability is included in Appendix B.

Due to the complexities in determining how far into the metastable region the fluid travels and the actual thermodynamic path that it takes, some models do not attempt to resolve this trajectory, but find other ways to account for the non-equilibrium effects ${ }^{8}$. In order to account for the finite rate of vapor bubble growth, Dyer et al. defined a characteristic bubble growth time as shown in Eqn. (6).

$$
\tau_{b} \equiv \sqrt{\frac{3}{2} \frac{\rho_{l}}{P_{v}-P_{2}}}
$$

The amount of vaporization that can occur within an injector element is dependent upon the ratio of the bubble growth time to the fluid residence time, which is inversely proportional to the velocity of the flow as shown in Eqn. (7).

$$
\tau_{r} \equiv \frac{L}{u}=\frac{L}{\sqrt{\frac{2 \Delta P}{\rho_{l}}}}=L \sqrt{\frac{\rho_{l}}{2 \triangle P}}
$$

By comparing the bubble growth time with the liquid residence time, Dyer et al. introduced a non-equilibrium parameter, $\boldsymbol{\kappa}$, which is shown in Eqn. (8).

$$
\kappa=\sqrt{\frac{P_{1}-P_{2}}{P_{v}-P_{2}}} \propto \frac{\tau_{b}}{\tau_{r}}
$$

The model first proposed by Dyer et al. and later corrected by Solomon accounts for non-equilibrium effects by allowing the flow rate to vary smoothly between that predicted by the Homogeneous Equilibrium Model and that of the single phase incompressible equation ${ }^{8,13}$. This form of the Dyer model is shown in Eqn. (9) and is referred to by Solomon as the Non-Homogeneous Non-Equilibrium (NHNE) model.

$$
\dot{m}_{D Y E R}=A\left(\frac{\kappa}{1+\kappa} \dot{m}_{S P I}+\frac{1}{1+\kappa} \dot{m}_{H E M}\right)
$$

This model attempts to account for the fact that when the residence time of bubbles $\tau_{r}$ is much less than the characteristic time for bubble growth $\tau_{b}$, very little vapor will be formed by the exit, and the single-phase assumption is likely valid. However, when $\tau_{b}<<\tau_{r}$, it is proposed that the flow rate should approach the critical value predicted by the Homogeneous Equilibrium Model. It has been observed that this is indeed the case for injectors with large length to diameter ratio $L / D$, which is attributed to the fact that there is more time for the fluid to reach thermodynamic equilibrium ${ }^{10}$. 
The Dyer model has been compared to a limited set of experimental hot fire test data at Stanford University and has demonstrated reasonable agreement. A constant $C_{d}$ of 0.66 was used, based on the average value for all of the injectors that were included. Even with an averaged discharge coefficient value, the model predicts mass flow rates with accuracy to within $\pm 15 \%$ for most tests ${ }^{8}$. However, better predictions are desired to assist in the development of full scale hybrid rockets using nitrous oxide.

Each of the models outlined above are conditionally useful, but a common shortcoming is the requirement for well characterized injector discharge coefficient data, which are often not available. While the discharge coefficient for most traditional rocket propellant injectors is well characterized, there is a great deal of uncertainty when it comes to the design and performance of nitrous oxide injectors. Additionally, there has been little in the way of model comparison and validation for injectors operating at realistic operating conditions with high vapor pressure propellants. While it is standard practice in the development of hybrid rockets to perform cold flow testing (oxidizer flow only, no ignition) in order to characterize a given injector design in terms of mass flow rate and atomization, most cold flow tests are not performed at the actual operating backpressure observed during combustion testing. Often cold flow tests are performed with the combustion chamber removed and the injector flowing to ambient pressure, resulting in a much larger $\Delta P$ than would be expected during tests involving combustion for the same hardware. As should be clear from the theoretical treatment above, the downstream pressure, $P_{2}$, and the pressure drop, $\Delta P$ are important parameters affecting the actual performance and modeling of injector mass flow.

The focus of this work now shifts to describe an experimental facility for the cold flow testing of nitrous oxide injectors at realistic operating pressures. The goal of this testing is to record and compile injector performance data over a broad range of operating conditions, which can be used to compare the accuracy of different mass flow rate prediction techniques described above and elsewhere in the literature. The experimental results from this apparatus will also be used to support the design efforts of hybrid rocket development programs at Stanford University and NASA Ames Research Center. Some initial results are presented for five injector designs.

\section{Experimental Setup}

\section{A. Test Apparatus}

In order to effectively characterize the mass flow rate performance of a variety of injector designs, a new facility has been developed to allow for the establishment of realistic operating pressures upstream and downstream of an interchangeable injector plate. Transparent polycarbonate tubes are closed on each end by aluminum end caps to create a pressure vessel with optical access $(\mathrm{ID}=25.4 \mathrm{~mm}$ ). This transparent setup was chosen to facilitate an ongoing study of nitrous oxide atomization using high-speed photography and laser illumination as described in previous work by the authors, the results of which will not be presented here ${ }^{3}$. The optical access allows for observations of the flow conditions upstream and downstream of the injector. A cut-away model of the test section is shown in Figure 4 along with a photo of the assembled hardware. Pressure and temperature are measured in both the upstream and downstream polycarbonate chambers at sampling rates from $500 \mathrm{~Hz}$ up to $5 \mathrm{kHz}$, allowing for the instantaneous measurement of $\Delta \mathrm{P}$ and determination of the upstream thermodynamic state. 


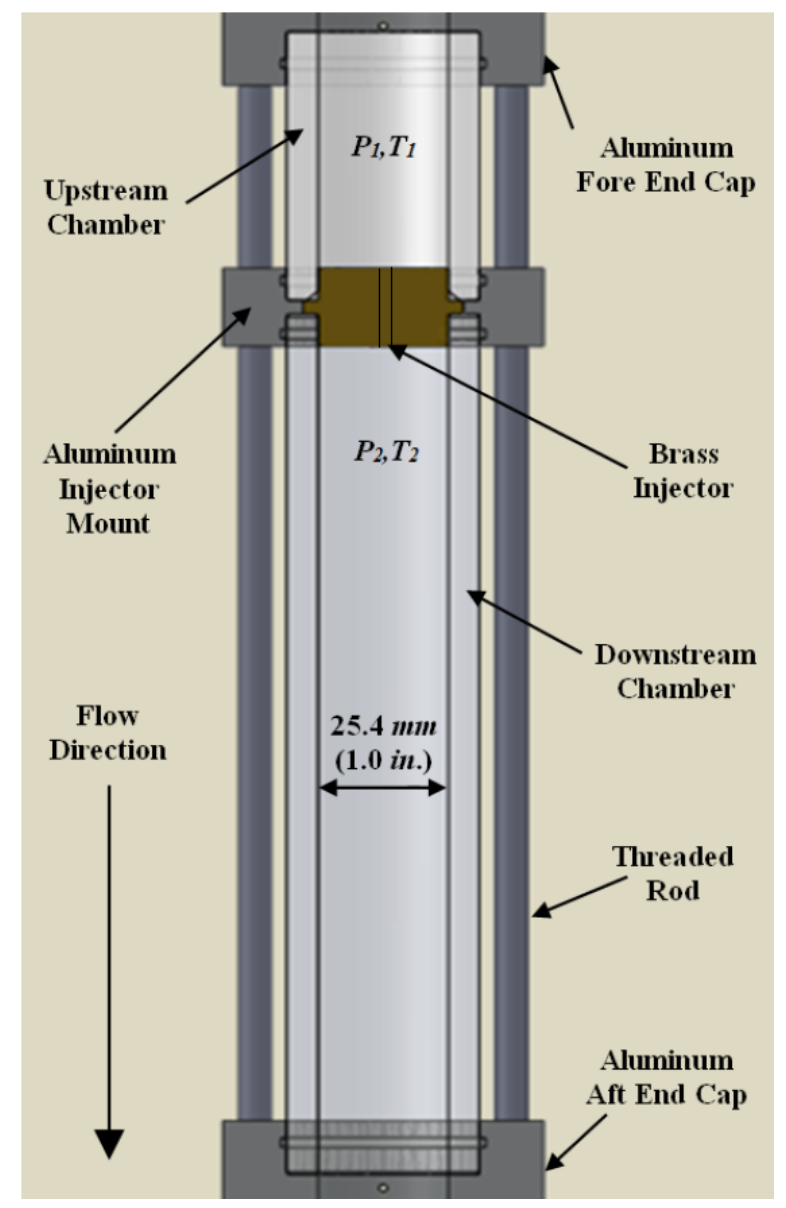

(a)

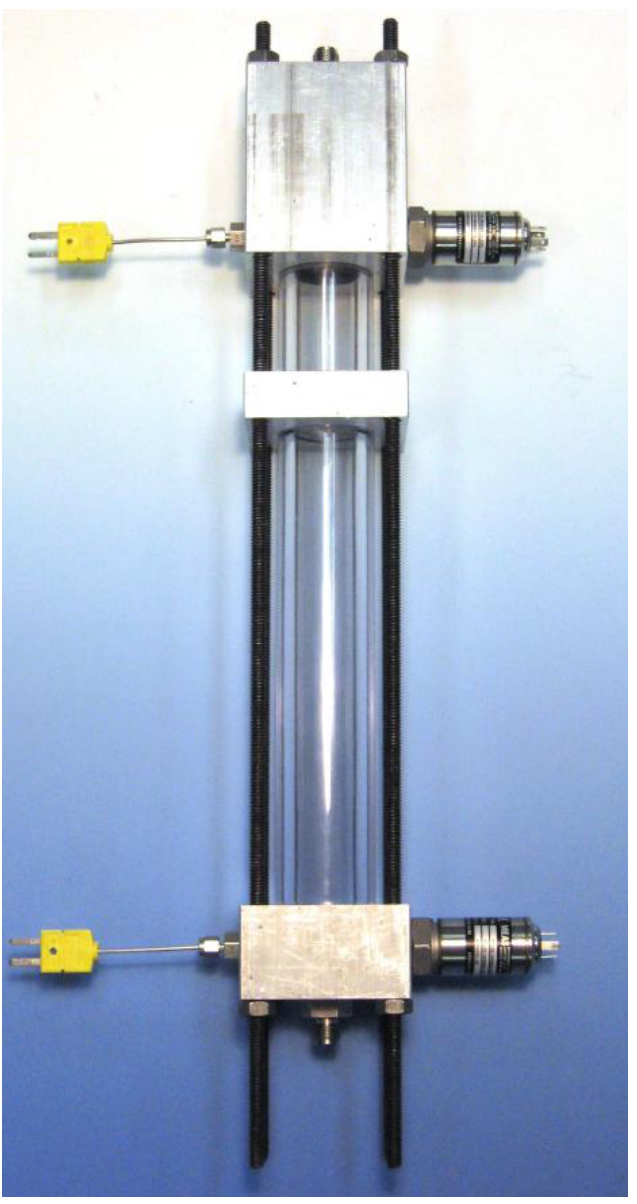

(b)

Figure 4. (a) Cut away view of the test section with main components labeled (b) Photo of the assembled hardware and instrumentation.

Liquid is supplied to the test section by a separate transparent pressure vessel which is also used for experiments investigating expulsion dynamics for self-pressurized propellant tanks. The tank is shown in Figure 5a and serves as an intermediate run tank between the test section and the compressed gas cylinders ( $\mathrm{K}$ size) that the nitrous oxide is delivered and stored in. More information on the tank dynamics experiments can be found in the work of Zimmerman et al. ${ }^{14,15}$ Liquid flows from the intermediate run tank to the test section through $6.35 \mathrm{~mm}$ diameter tubing, a pneumatically actuated ball valve, and a venturi flow meter. A standard pressure transducer and a differential pressure transducer are used in conjunction with the venturi to calculate mass flow rate. A photo of the full system setup is shown in Figure 5b.

The run tank is filled using a pneumatically driven pump, but under certain conditions the self-pressurization within the storage tank is sufficient to drive the nitrous oxide into the run tank. Many practical systems employ supercharging in order to avoid cavitation in the feed system caused by localized pressure drops. In order to sub-cool the liquid in this fashion, the run tank can be pressurized with helium up to approximately $1000 \mathrm{psig}$ ( $7.00 \mathrm{MPa}$ ). The pressurization system allows for flexibility when it comes to setting the thermodynamic state of nitrous oxide in the tank and upstream of the injector. Helium is widely chosen as the supercharging gas in practical pressurization systems due to its low molecular weight. However, if helium becomes dissolved in a self-pressurizing propellant there can be significant effects on cavitation due to helium desorption throughout feed system ${ }^{16}$. In current tests, it is believed that helium is not appreciably dissolved in the nitrous oxide because of the short time between supercharging and completion of the test. Nevertheless, future work will address the potentially undesirable effects of helium absorption and desorption with regard to cavitation and mass flow rate. A process and instrumentation diagram (P\&ID) with more details on the fluid handling and instrumentation of the system can be found in the previous work of Waxman et al. ${ }^{3}$ 


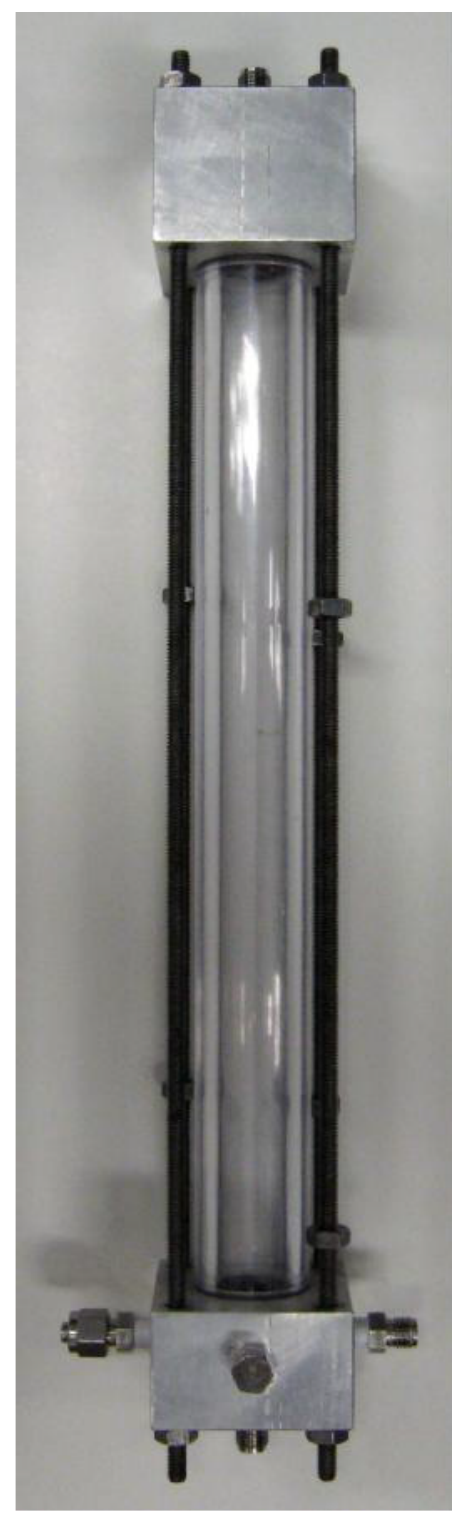

(a)

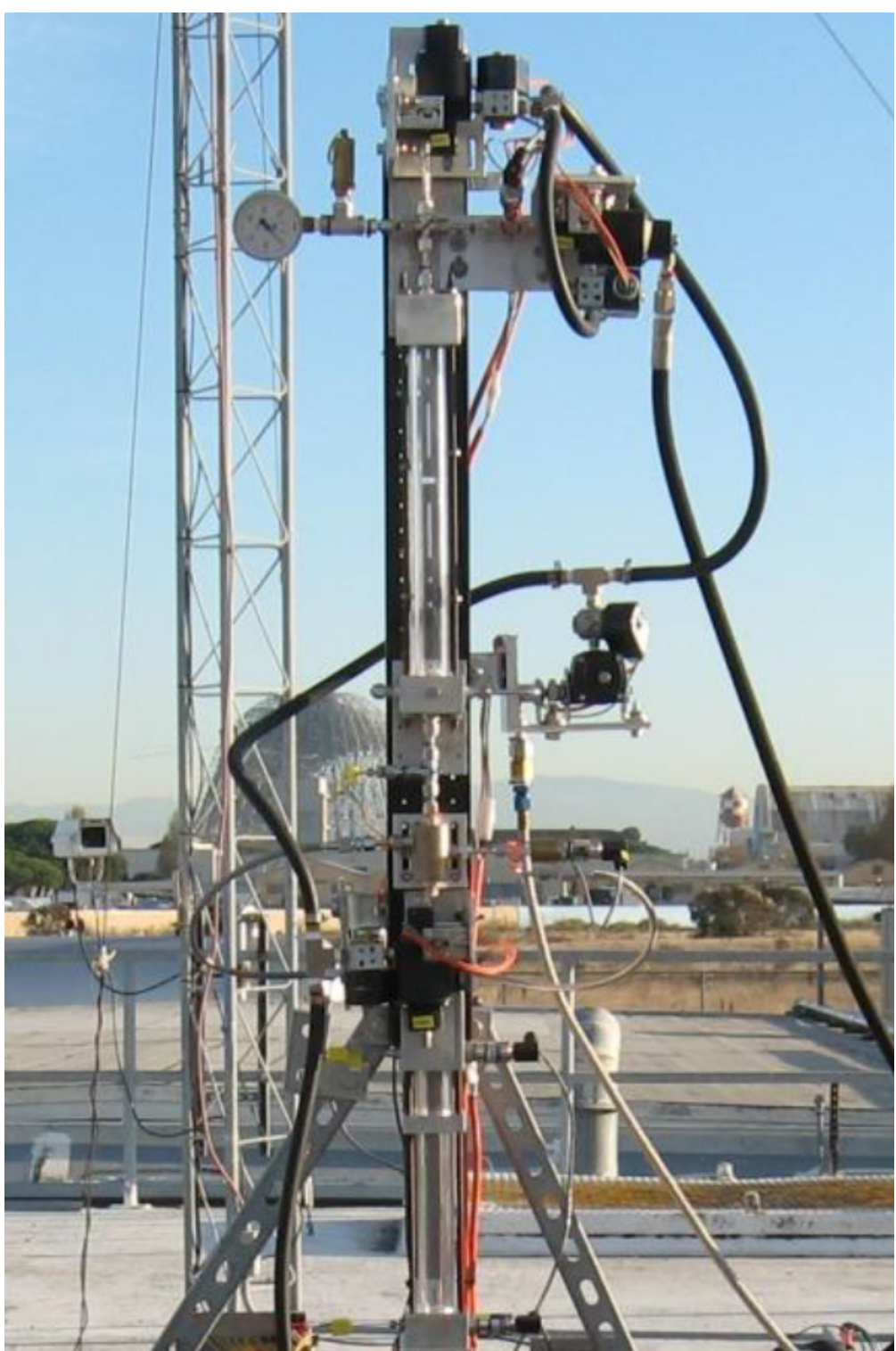

(b)

Figure 5. Photos of (a) the intermediate run tank and (b) the overall system setup. 
In order to allow for the testing of a wide range of injector designs, an injector insert was designed to be easily interchangeable. The brass insert is mounted within an aluminum block that serves as the junction between the upstream and downstream polycarbonate pressure vessels as shown above in Figure 4a. Silicone O-rings are used to provide seals at each junction. A large assortment of injector inserts have been manufactured for testing in this facility. The first injectors tested in this rig were designed to investigate mass flow rate characteristics with the variation of injector orifice diameter $D$ and hole inlet geometry (square edged, rounded, chamfered). For this work, the length $L$ of each injector hole was fixed at a value of $18.4 \mathrm{~mm}$. However, future work will study the effect of varying overall injector length. All of the injectors used in these tests were simple straight hole orifices. Table 1 details the geometry of each injector tested in this work. Rounding on the injector inlets was at a radius of $0.51 \mathrm{~mm}$ and chamfers were machined at $45^{\circ}$ to a depth of $0.76 \mathrm{~mm}$. A photo of one injector insert is shown in Figure 6

Table 1. Description of injector design geometry.

\begin{tabular}{cccccc}
\hline Number & Style & $D[\mathrm{~mm}]$ & $L[\mathrm{~mm}]$ & $L / D$ & Entrance Geometry \\
\hline \hline$(1)$ & Straight & 0.79 & 18.4 & 23.4 & Square Edge \\
\hline$(2)$ & Straight & 1.50 & 18.4 & 12.3 & Square Edge \\
\hline$(3)$ & Straight & 1.50 & 18.4 & 12.3 & Rounded \\
\hline$(4)$ & Straight & 1.50 & 18.4 & 12.3 & Chamfered \\
\hline (5) & Straight & 1.93 & 18.4 & 9.5 & Square Edge \\
\hline
\end{tabular}

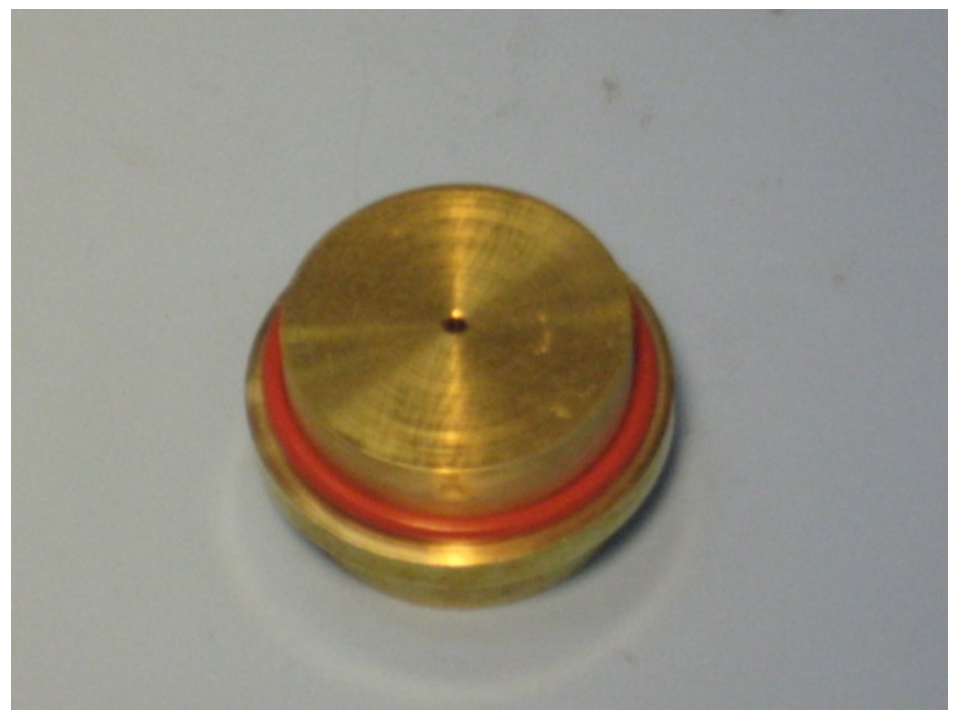

Figure 6. Photo of injector insert 3 with corner O-ring installed.

\section{B. Carbon Dioxide as an Analog to Nitrous Oxide}

Although nitrous oxide has properties that make it an attractive oxidizer choice for hybrid rockets, it is still a reasonably strong oxidizer and its use does pose some significant risks. Specifically, nitrous oxide has a positive heat of formation, and the potential exists for rapid exothermic decomposition. This type of runaway decomposition reaction can lead to violent and dangerous pressure vessel explosions. Multiple groups have studied these explosive events and have concluded that despite the potential hazards, nitrous oxide can be used safely with proper handling considerations $^{2,17}$. Stringent cleaning procedures such as those used for oxygen systems must be followed in order to minimize the possibility of explosions. However, these types of explosions do happen in the hybrid rocket industry, and have caused major hardware damage and even fatalities. Therefore, the use of nitrous oxide is not always ideal in an academic setting, and is sometimes restricted to certain areas as a means for ensuring student safety. 
Fortunately, multiple groups have recognized that carbon dioxide can be used as a safe analog to nitrous oxide when it comes to fluid flow studies ${ }^{13,14}$. Nitrous oxide and carbon dioxide are quite similar thermodynamically in that they have almost the same molecular weight and exhibit less than 5\% variation in most of the important thermodynamic properties listed in Table 2. However, some thermodynamic parameters do differ greatly, such as the triple point and the acentric factor. The acentric factor is a measure of the aspherical nature of a molecule, and its tendency to behave differently than simple monatomic fluids. The difference in acentric factor between nitrous oxide and carbon dioxide can contribute to the difference in properties such as saturation pressure and vapor density ${ }^{18}$. As seen in Figure 7 , these two values can differ upwards of $15 \%$ when nearing the critical point (though saturated liquid density matches quite closely). An in depth comparison of nitrous oxide and carbon dioxide thermodynamic and transport properties away from the saturation line is performed by Zimmerman et al. and has been applied to look at the effect of using carbon dioxide as an analog during propellant tank blow-down experiments ${ }^{15}$.

Table 2. Comparison of important thermodynamic properties of $\mathrm{N}_{2} \mathrm{O}$ and $\mathrm{CO}_{2} 6,7,19,20$

\begin{tabular}{lcccc}
\hline Property & Units & Nitrous Oxide $\left(\mathrm{N}_{2} \mathrm{O}\right)$ & Carbon Dioxide $\left(\mathrm{CO}_{2}\right)$ & Difference $(\%)\left(\frac{\mathrm{CO}_{2}-\mathrm{N}_{2} \mathrm{O}}{\mathrm{N}_{2} \mathrm{O}}\right)$ \\
\hline \hline$M$ & $\mathrm{amu}$ & 44.013 & 44.010 & -0.007 \\
\hline$P_{c}$ & psia $(\mathrm{MPa})$ & $1050.8(7.25)$ & $1070.0(7.38)$ & +1.80 \\
\hline$P_{\text {trip }}$ & psia $(\mathrm{MPa})$ & $12.7(0.088)$ & $75.1(0.518)$ & +491 \\
\hline$T_{c}$ & $\mathrm{~K}$ & 309.6 & 304.2 & -1.74 \\
\hline$T_{\text {trip }}$ & $\mathrm{K}$ & 182.3 & 216.6 & +18.8 \\
\hline$\rho_{c}$ & $\frac{\mathrm{kg}}{\mathrm{m}^{3}}$ & 452.0 & 467.6 & +3.45 \\
\hline$Z_{c}$ & & 0.273 & 0.274 & +0.366 \\
\hline$\omega$ & & 0.160 & 0.225 & +40.6 \\
\hline
\end{tabular}

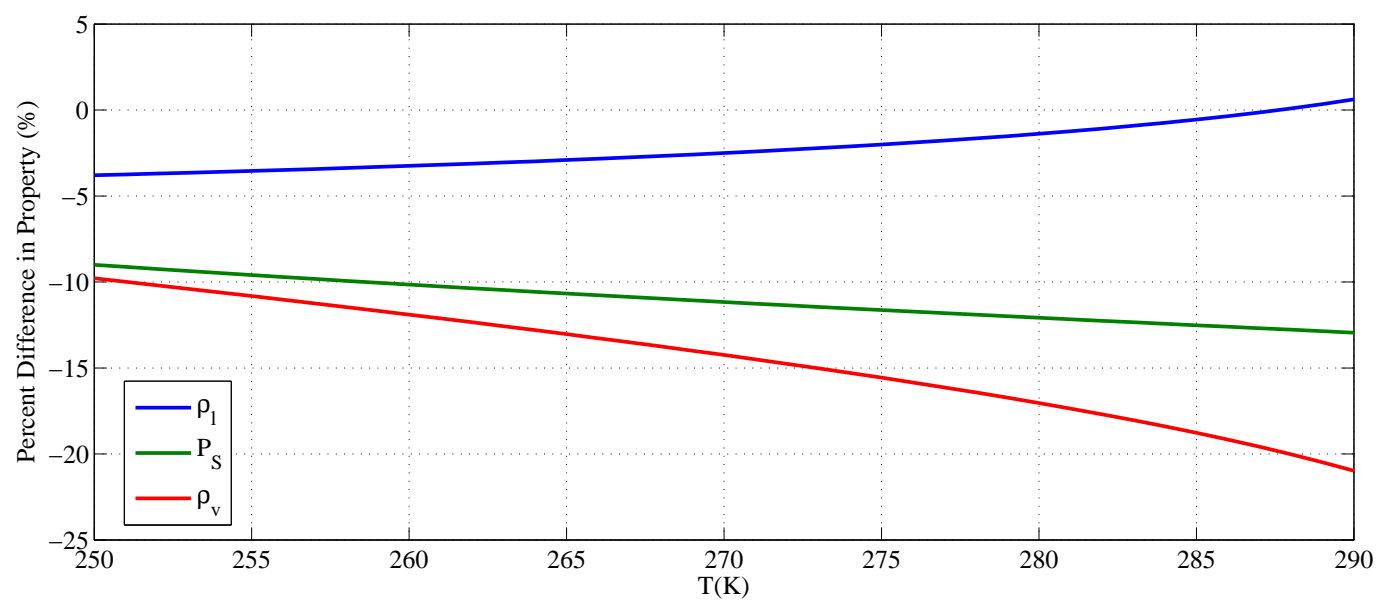

Figure 7. Percent difference in saturated vapor density, liquid density, and saturation pressure $\left(\mathrm{P}_{s}\right)$ for $\mathrm{CO}_{2}$ as an analog to $\mathrm{N}_{2} \mathrm{O}$. (Oxidizer temperatures ranging from $250 \mathrm{~K}$ to $290 \mathrm{~K}$ are of particular interest for large scale hybrid rocket systems using $\left.\mathrm{N}_{2} O\right)^{6,7,19,20}$.

While the thermodynamic similarities are encouraging, experimental comparisons must be performed to quantify the effects of using carbon dioxide as an analog to nitrous oxide before work can be moved solely to carbon dioxide. This work will provide some initial comparisons of injector performance with the use of carbon dioxide versus nitrous oxide. To accommodate testing with nitrous oxide while ensuring the safety of all involved, this work was performed at the Outdoor Aerodynamic Research Facility (OARF) at NASA Ames Research Center in Moffett Field, CA. Experiments are controlled remotely with all personnel in a bunker $150 \mathrm{ft}$ away from the test stand. 


\section{Test Method and Data Processing}

The procedure for tests involving nitrous oxide is described below. However, the same process is used for carbon dioxide and the name of the fluid can be substituted at will. The only significant difference in operating with nitrous oxide is the strict cleaning and anti-contamination procedures that are used when handling hardware (not described here).

\section{Test Preparation}

A typical test is prepared by filling the run tank with nitrous oxide to a desired level using the pneumatically driven pump. If it is necessary to establish a desired liquid temperature, the nitrous oxide storage cylinder can be either heated or cooled using an insulated water bath prior to and throughout the test. Next, the helium pressurization system is used to provide the target supercharge level. It is useful at this point to introduce a local supercharge pressure, which is defined as the instantaneous difference between the static pressure and the vapor pressure of nitrous oxide at a given point in the system. The expression for the supercharge pressure at in the pre-injector volume located just upstream of the injector is shown in Eqn. (10), where the vapor pressure is evaluated at the local instantaneous temperature $\left(T_{1}\right.$ in this case).

$$
P_{\text {super }}^{1}=P_{1}-\left.P_{s}\right|_{T=T_{1}}
$$

Aside from an exhaust valve that opens to ambient, the downstream chamber labeled in Figure 4a is a closed vessel. The exhaust valve is generally kept closed throughout the duration of a test and if desired, the downstream chamber and pre-injector volume can be pre-pressurized with nitrogen to establish elevated backpressures at the beginning of a test.

\section{Running a Test}

Once the desired tank and chamber conditions are established, the pneumatically actuated ball valve that connects the run tank to the test section is opened to initiate a test. Nitrous oxide immediately begins to fill the pre-injector volume, and $P_{1}$ rises rapidly to a level approximately equal to that of the run tank. At the same time, nitrous oxide is flowing through the injector and the downstream pressure $P_{2}$ starts to rise. Because $P_{1}$ increases much faster than $P_{2}$, a large pressure drop $\Delta P$ is established across the injector, nearing $1000 \mathrm{psi}(6.89 \mathrm{MPa})$ in some instances. However, because the exhaust valve is closed and the chamber is filling up with liquid nitrous oxide, the downstream pressure will continue to rise until $P_{1}=P_{2}$, at which point the pressure drop across the injector is zero and flow stops, completing the test. By operating in this dynamic fashion, a single test can provide a broad sweep of downstream operating pressures for constant upstream conditions. A typical pressure time history is shown in Figure 8 (valve opens at approximately $0.5 \mathrm{~s}$ ).

Once the ball valve is opened, there is a rush of nitrous oxide flow into the pre-injector volume. As the liquid front of nitrous oxide expands rapidly into the pre-injector volume, much of it flashes to vapor, resulting in rapid cooling and low temperatures for a short duration in the beginning of a test as shown in Figure 9. However, once the ensuing liquid fills in the volume upstream of the injector, the temperature returns to the bulk liquid temperature and stabilizes. Because the pressure transducers used in this region are susceptible to rapid changes in temperature, it is important to provide thermal insulation to ensure accurate pressure measurements. Synthetic lubricant (Krytox) is applied to the pressure transducer cavities in order to provide thermal insulation without impacting the accuracy of the measurements.

\section{Data Analysis}

While the pre-injector volume is filling with liquid nitrous oxide, the flow is only limited by the feed line diameter and a high mass flow rate is fed through the system. These high mass flow rates during the beginning of a test are reflected in the venturi flow rate measurements as seen in Figure 10a from approximately $0.5 \mathrm{~s}$ until $0.6 \mathrm{~s}$. Not until this 


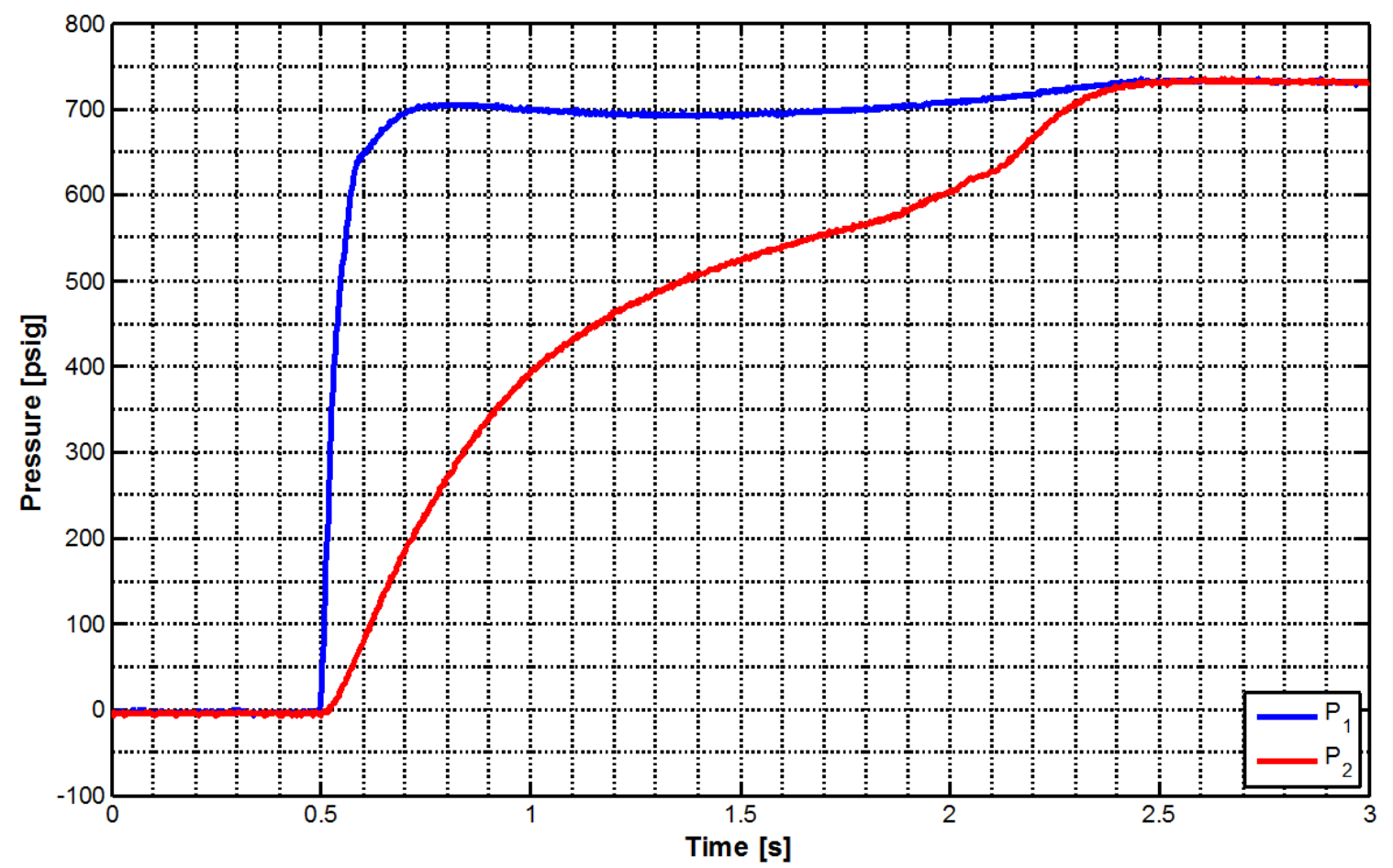

Figure 8. Pressure time histories for positions upstream and downstream of the injector during a typical test.

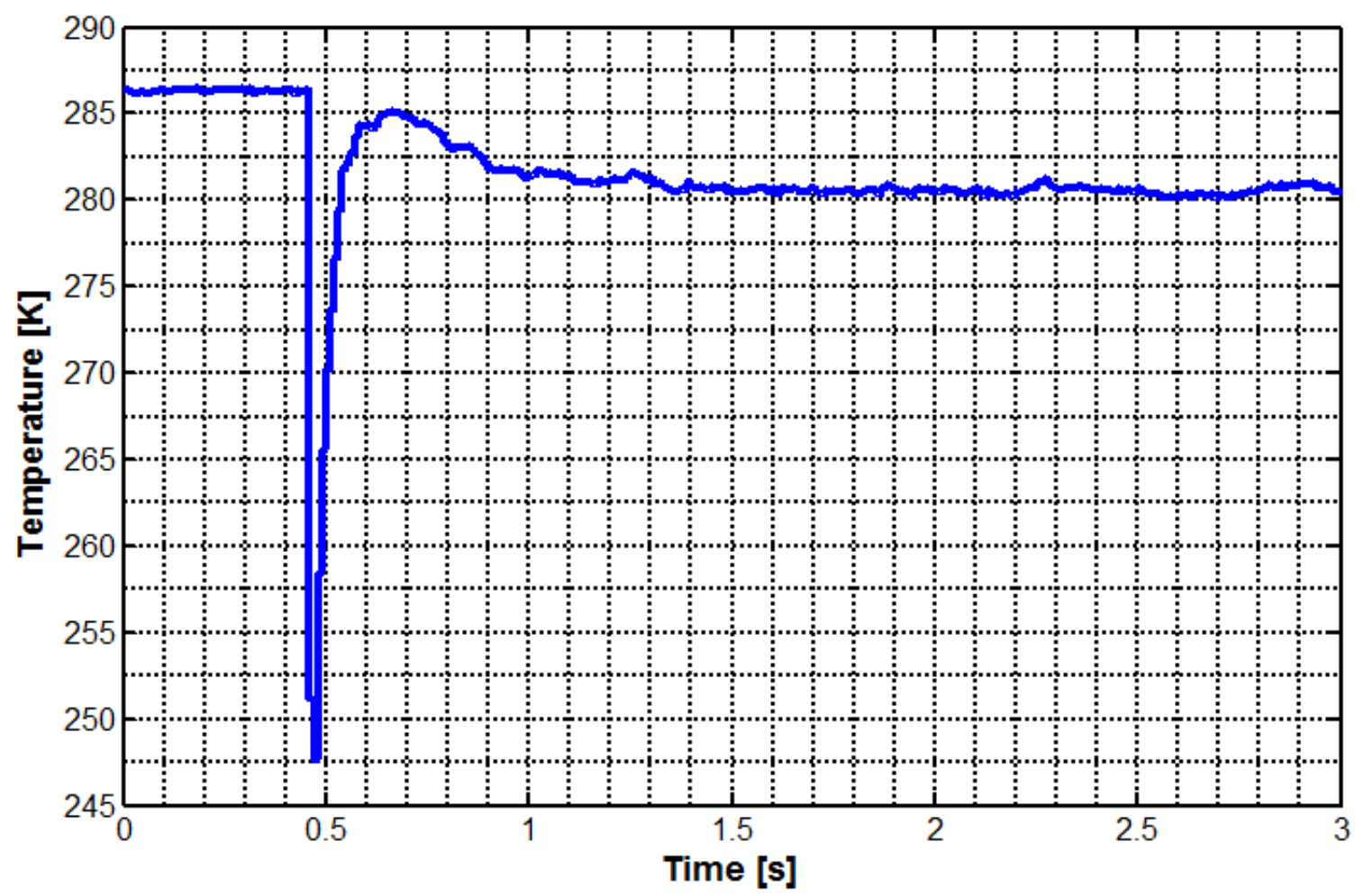

Figure 9. Typical time history of $T_{1}$ (minimum temperature of $247 \mathrm{~K}$ ). 
volume is completely filled with liquid does the injector become the mass flow limiting device, and thus the venturi mass flow rate measurements can only be used from this point onwards during a test. For this reason, the test data used for analysis must be selected appropriately. A typical cropping of the data is shown by the highlighted segments in Figure 10a and Figure 10b which correspond to the same test as Figure 9. The test depicted in these figures is for nitrous oxide flow through injector number 3 , the geometry of which is described in Table 1.

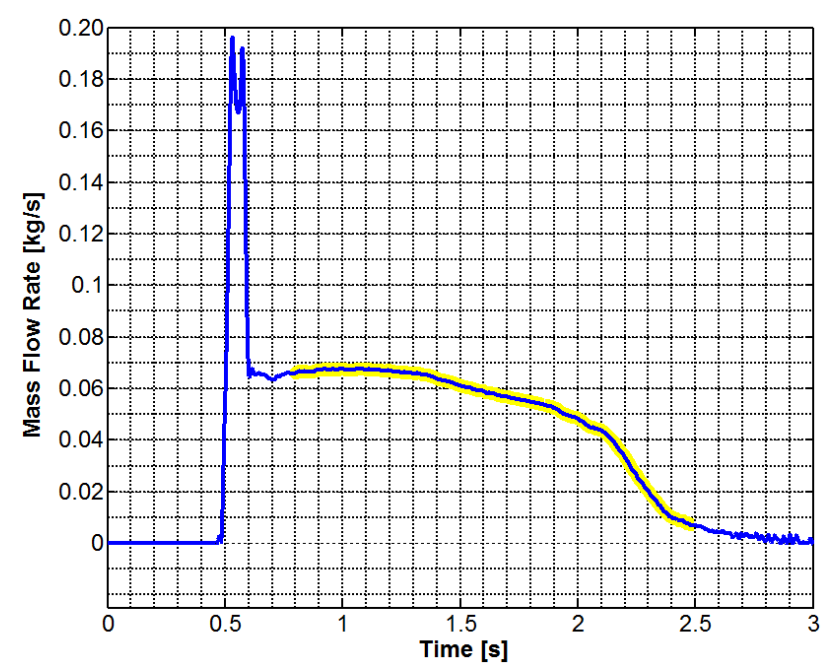

(a)

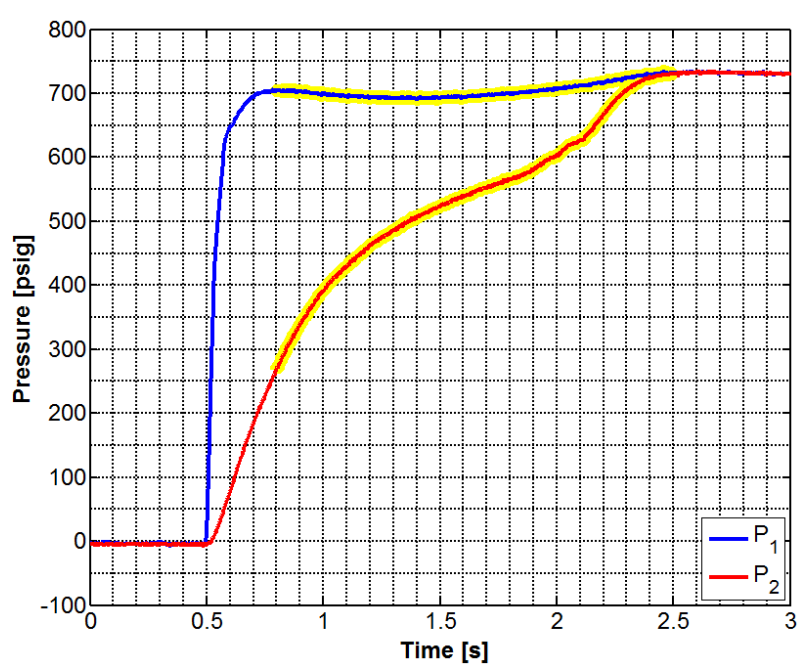

(b)

Figure 10. (a) Mass flow rate time history and (b) pressure time history for a typical test of nitrous oxide flow through injector number 3.

Looking carefully at the plots in Figure 10, it can be seen that in the early portions of the cropped section, $\Delta P$ is dropping rapidly while the mass flow remains relatively constant. When the mass flow data is plotted versus the pressure time history, it is much easier to examine the behavior of the injector. This type of analysis results in a plot of the form shown in Figure 11, created from the cropped sections above. This data corresponds to average upstream values of $P_{1}=704 \mathrm{psig}(4.96 \mathrm{MPa}), T_{1}=280 \mathrm{~K}$, and $P_{\text {super }}^{1}=169 \mathrm{psi}(1.26 \mathrm{MPa})$. While the instantaneous values for the upstream parameters do shift a small amount during a test, for simplicity the injector performance will be studied based on the average upstream values and the instantaneous downstream values. In a similar fashion it possible to plot the effective discharge coefficient versus $\Delta P$ as shown in Figure 12. This effective discharge coefficient is defined by dividing the instantaneous mass flow rate during the test by the value calculated assuming single-phase incompressible flow and a discharge coefficient of 1 . As $\Delta P$ and mass flow rate approach zero the effective discharge coefficient shows a great deal of scatter and this region is ignored for the purposes our analysis.

The plots above are useful in identifying the different flow regimes. For low values of $\Delta P, 30 \mathrm{psi}<\Delta P<200 \mathrm{psi}$ in this case $(0.207 \mathrm{MPa}<\Delta P<1.38 \mathrm{MPa})$, the flow is well described by the SPI model. The experimental data in this region can be fit to Eqn. (2) by determining the SPI discharge coefficient for this combination of injector geometry and upstream thermodynamic conditions ( $C_{d} \approx 0.77$ in this case). The red line in Figure 11 corresponds to the mass flow rate predicted by the SPI model using this discharge coefficient. While the SPI model is not physically valid in the two-phase flow region past the critical $\Delta P$, the results from Figure 12 allow one to calculate an effective discharge coefficient for use in the two-phase region. For example, the effective discharge coefficient for injector number 3 at the upstream conditions presented above drops to a value of approximately 0.6 at a pressure drop of $330 \mathrm{psi}$ (2.28 $\mathrm{MPa})$. For large values of $\Delta P$, it is clear that we do in fact see the same critical flow effect shown by Hesson and Peck and predicted by the HEM and Dyer models. As seen in the figures above, a region is identified indicating the transition from the single-phase mode into the multiphase regime. The limits of this region are based on the deviation of discharge coefficient away from the calculated SPI value and are defined below:

Transition $\Delta P$ : Value of $\Delta P$ for which the effective discharge coefficient first drops below $99 \%$ of the SPI value.

Critical $\Delta P$ : Value of $\Delta P$ for which the effective discharge coefficient first drops below $95 \%$ of the SPI value. 


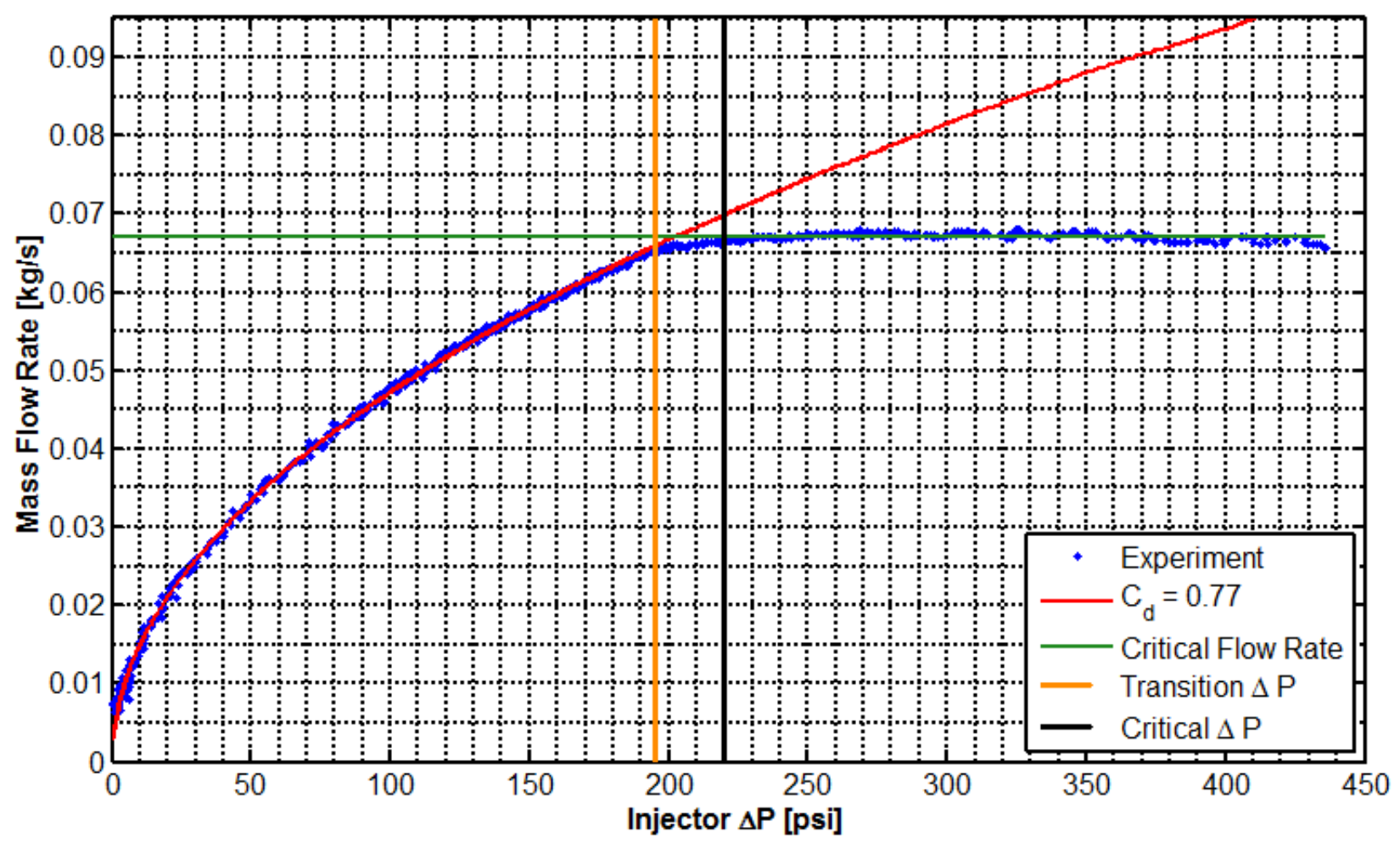

Figure 11. Nitrous oxide mass flow rate vs. injector $\Delta P$ data for a test of injector number 3 at average upstream values of $P_{1}=704$ psia (4.85 MPa), $T_{1}=280 \mathrm{~K}$ and $P_{\text {super }}^{1}=169 \mathrm{psi}(1.17 \mathrm{MPa})$.

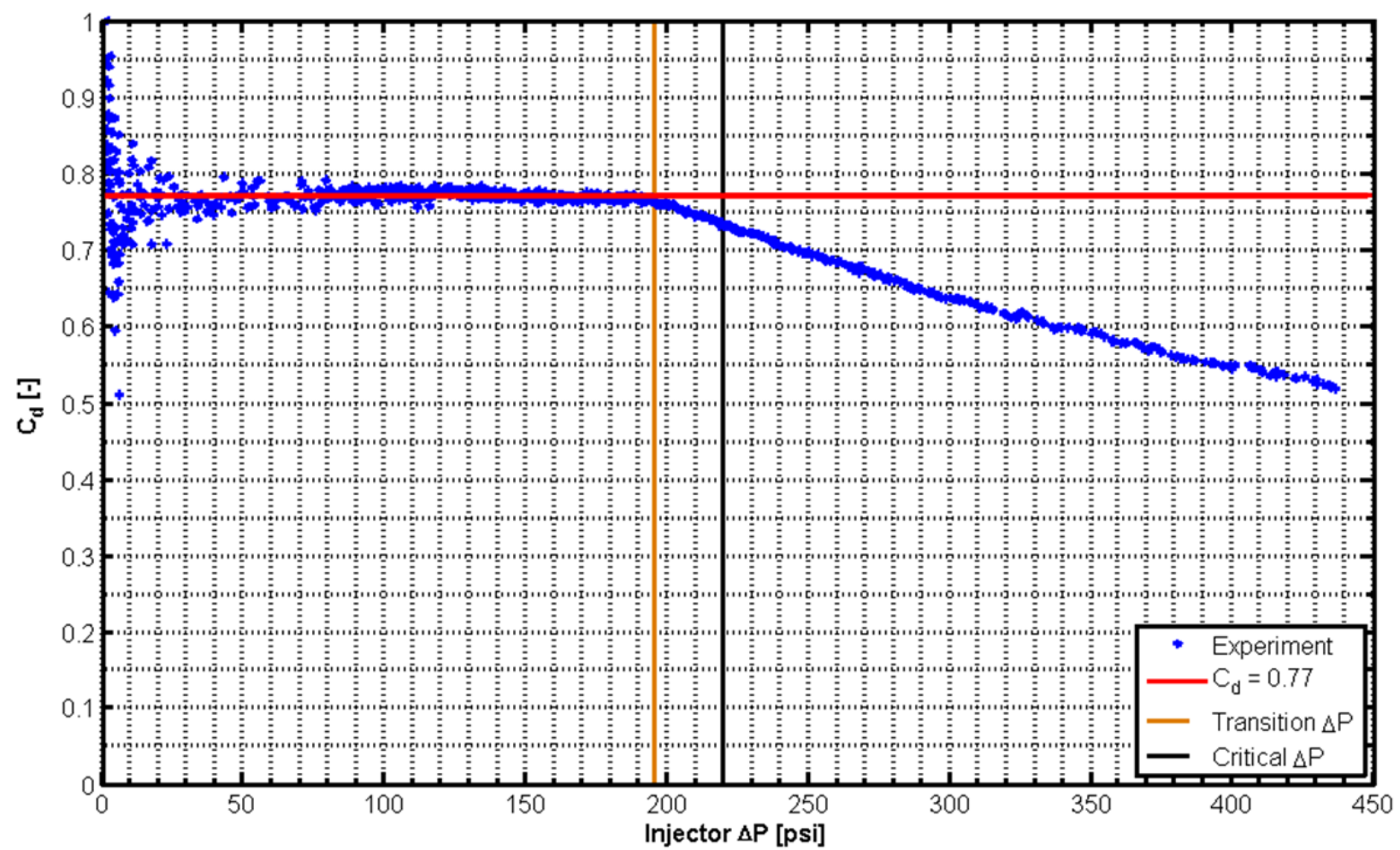

Figure 12. Effective discharge coefficient vs. injector $\Delta P$ data for a test of injector number 3 at average upstream values of $P_{1}=704$ psia (4.85 MPa), $T_{1}=280 \mathrm{~K}$ and $P_{\text {super }}^{1}=169 \mathrm{psi}(1.17 \mathrm{MPa})$. 
The plots above can be used directly to assist in the design of injectors, however only for the specific upstream pressure and supercharge used in this test and with a rounded inlet injector. This type of test and data processing can be repeated for a multitude of upstream conditions and injector configurations in order to create a catalog of performance data for use in the design of injectors, or for validation of predictive models. The following section presents the initial results that are to be included in an injector performance database, along with some basic comparisons.

\section{Mass Flow Rate Characterization}

To date over 500 tests have been performed in this new facility, using both nitrous oxide and carbon dioxide as test fluids. Experiments have been performed over a wide range of operating conditions:

$P_{1}: \quad 450 \mathrm{psig} \rightarrow 1000 \mathrm{psig}(3.20 \mathrm{MPa} \rightarrow 7.00 \mathrm{MPa})$

$P_{2}: \quad 0$ psig $\rightarrow 1000$ psig $(0.101 \mathrm{MPa} \rightarrow 7.00 \mathrm{MPa})$

$T_{1}: \quad 265 \mathrm{~K} \rightarrow 298 \mathrm{~K}$

$P_{\text {super }}^{1}: \quad 0 \mathrm{psi} \rightarrow 500 \mathrm{psi}(0 \mathrm{MPa} \rightarrow 3.45 \mathrm{MPa})$

As described in the previous section, a single test provides a sweep of downstream conditions and a vast amount of injector performance data. In order to cover as much of the design space as possible, a range of tests at different supercharge pressures were performed for a given injector design. Figure 13 provides the resulting experimental nitrous oxide mass flow rate data for injector number 3 at a variety of supercharges, plotted against $\Delta P$. This figure is created by combining a number of plots similar to that shown in Figure 11, and the same data processing is performed for each curve (the labeling of flow transition and critical mass flow rate however are not included in this plot). Starting at $\Delta P$ $=0$ and moving up and to the right, it is evident that at low values of $\Delta P$, each test follows the single-phase behavior, and the mass flow rate is relatively independent of supercharge. However, continuing up the curve, we encounter the critical $\Delta P$ corresponding to the lowest supercharge test, in this case $P_{\text {super }}^{1}=41 \mathrm{psi}(0.283 \mathrm{MPa})$, after which point the mass flow rate deviates from the single-phase curve, and critical flow is encountered. This process continues while moving up the curve, and the results from each test deviate from the single-phase behavior in order from lowest to highest supercharge. It becomes clear that as $P_{\text {super }}^{1}$ increases, so too does the critical mass flow rate and critical $\Delta P$. From the same test data the effective discharge coefficient is calculated and is plotted versus supercharge and $\Delta P$ as shown in Figure 14. The behavior of the $C_{d}$ curves can be examined in the same fashion, following the single-phase behavior until it deviates at the critical $\Delta P$ value.

At this point it should be noted that all tests reported in this work are for non-zero values of supercharge. There are two main reasons for this: (a) For tests with saturated liquid, large amounts of vapor are formed within the run tank, leading to unreliable venturi mass flow rate measurements, and (b) with only pressure and temperature measurements upstream of the injector, it is not possible to determine the vapor fraction needed for completely describing the thermodynamic state of the fluid. The minimum supercharge used for this work is approximately $41 \mathrm{psi}(0.283 \mathrm{MPa})$. The same plots presented above can be created for each combination of injector and fluid. For reference information, all of the data produced during experiments for this work are included in an appendix of previous work by the authors ${ }^{4}$. An in depth analysis of results was also presented in the same work, but the following sections will highlight some of the important analyses by (a) first examining tests using nitrous oxide to investigate the effect of injector hole diameter $D$, (b) assessing the validity of using carbon dioxide as an analog to nitrous oxide in order to (c) use the results from tests with carbon dioxide to examine the effect of injector inlet geometry. Finally, the experimental data will be compared to the results from Dyer model presented earlier in this work. 


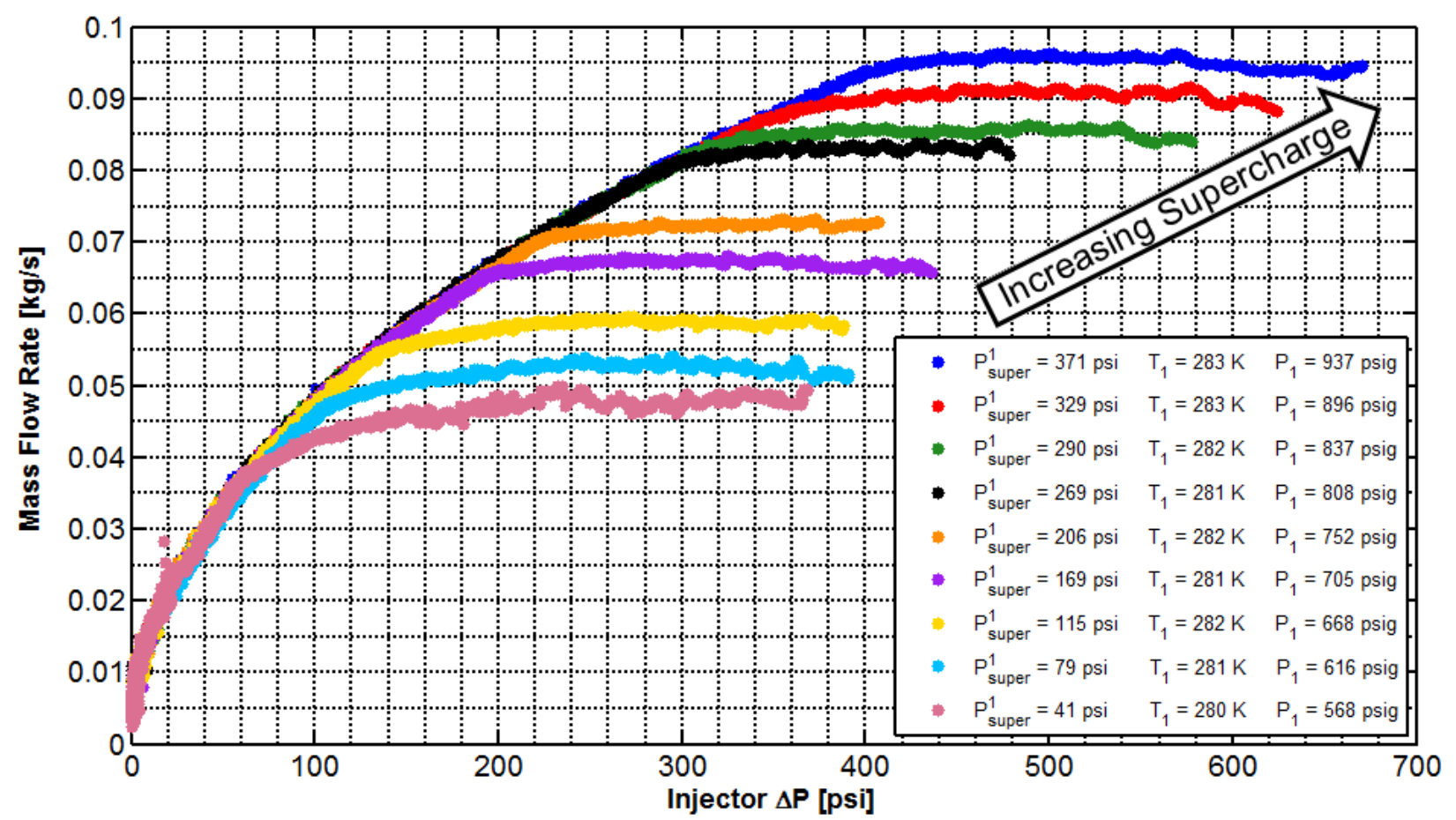

Figure 13. Mass flow rate vs. $\Delta P$ at various supercharge levels for injector number 3 with nitrous oxide.

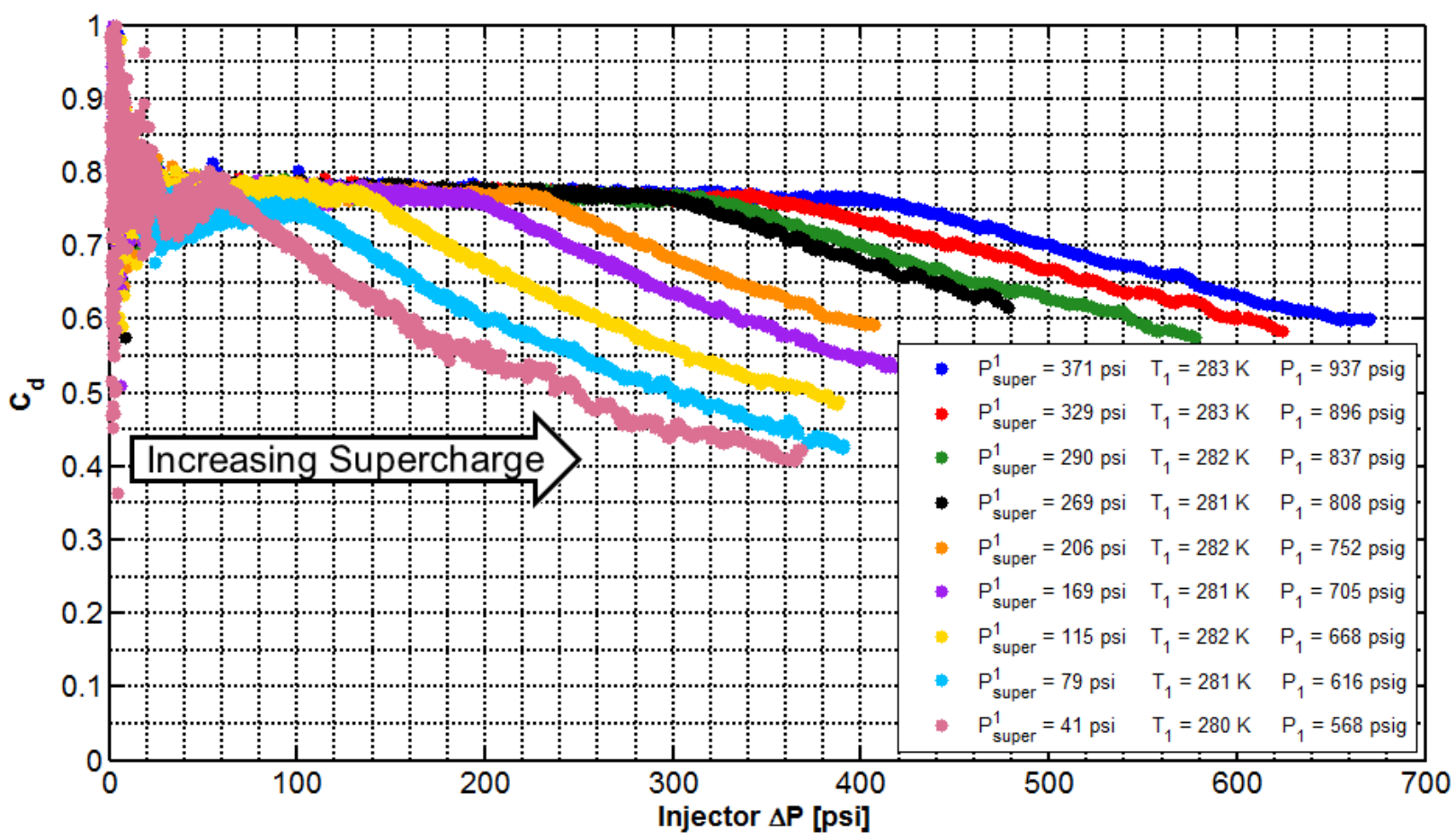

Figure 14. $C_{d}$ vs. $\Delta P$ at various supercharge levels for injector number 3 with nitrous oxide. 


\section{A. Effect of Injector Hole Diameter}

Figure 15 shows the SPI discharge coefficient over a range of supercharge values for three different injectors, all square edged orifices with varying diameters. While there is virtually no dependence on supercharge, it can be seen that $C_{d}$ decreases with increasing hole diameter. It cannot be determined from these tests alone whether the effect is due to the difference in hole diameter or the difference in hole length to diameter ratio, $L / D$ (future work will address this subject). While it may seem like this result could be an artifact of including the denominator from Eqn. (1) in the discharge coefficient, even with largest diameter orifices tested, this effect should only account for an error of approximately $0.002 \%$ in the combined discharge coefficient. However, it is likely that this inverse relationship is due to either Reynolds number effects or geometric scaling related to the vena contracta dimensions. All of these tests were performed using nitrous oxide.

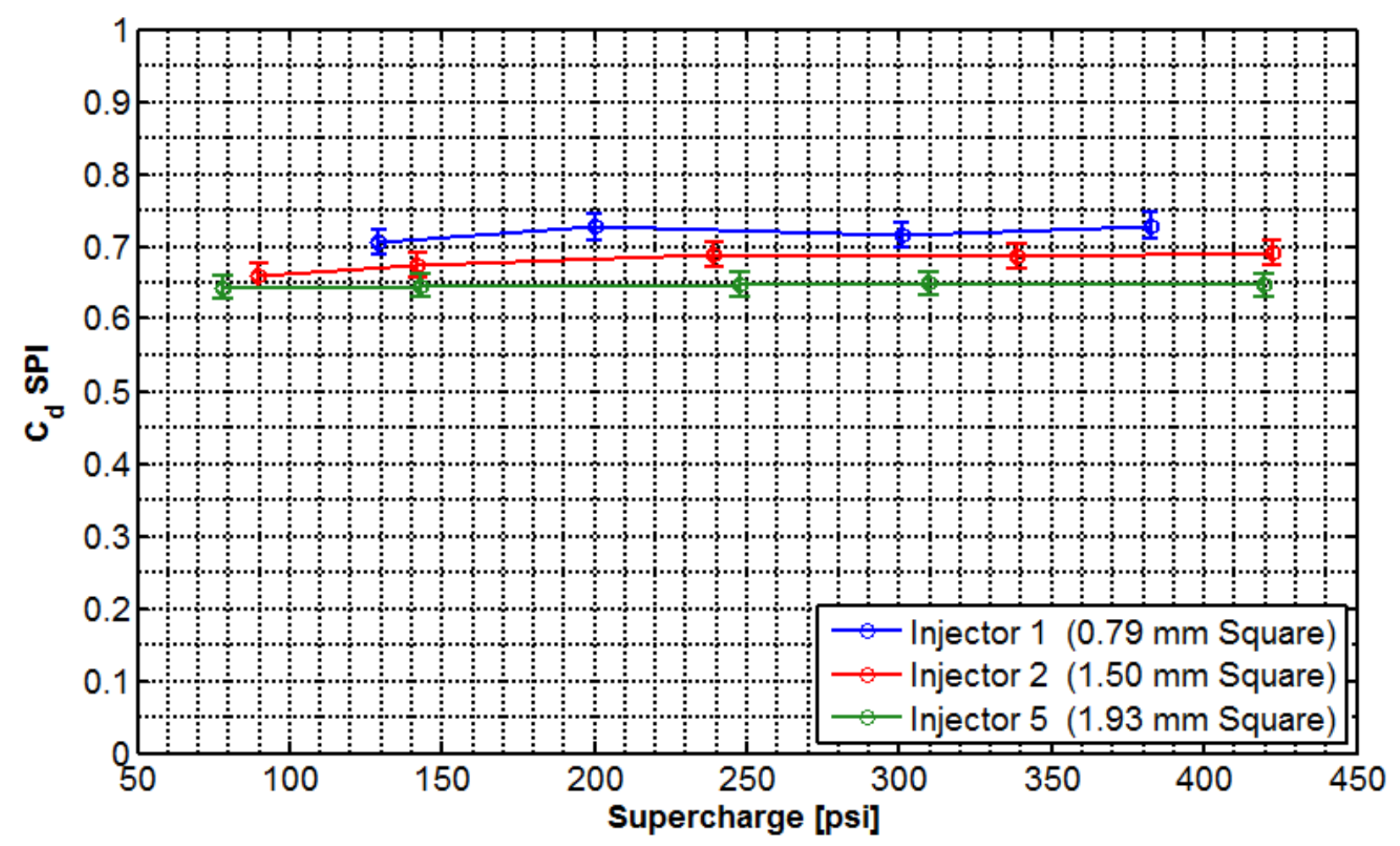

Figure 15. $C_{d}$ in the single-phase region vs. supercharge for injectors number 1,2 and 5 with nitrous oxide.

\section{B. Comparison of Results with Nitrous Oxide and Carbon Dioxide}

Next we will take a look at some results that will help to determine whether or not carbon dioxide can be used as an effective analog to nitrous oxide. In contrast to the results presented above, these tests will be for a single injector geometry, and the fluid will be varied. Injector number 3 was used for this analysis. Figure 16 plots the critical mass flow rate versus supercharge for both carbon dioxide and nitrous oxide. The critical mass flow rate of carbon dioxide does tend to be slightly higher than for nitrous oxide. However, this comparison ignores the fact that there is a slight variation in density between the two fluids. Even so, the difference in critical mass flow rate between carbon dioxide and nitrous oxide is less than $10 \%$ for the whole range of supercharge values tested. Additionally, Figure 17 compares the discharge coefficient for the single-phase region of these tests and for most supercharge levels the value is identical. At points where the discharge coefficient does vary between carbon dioxide and nitrous oxide, the values generally differ by less than 5\%. It can be concluded from the results presented in Figure 16 and Figure 17 that carbon dioxide is indeed a relatively accurate analog, though small differences in performance do exist. Future testing may serve to provide correlations between nitrous oxide and carbon dioxide performance. 


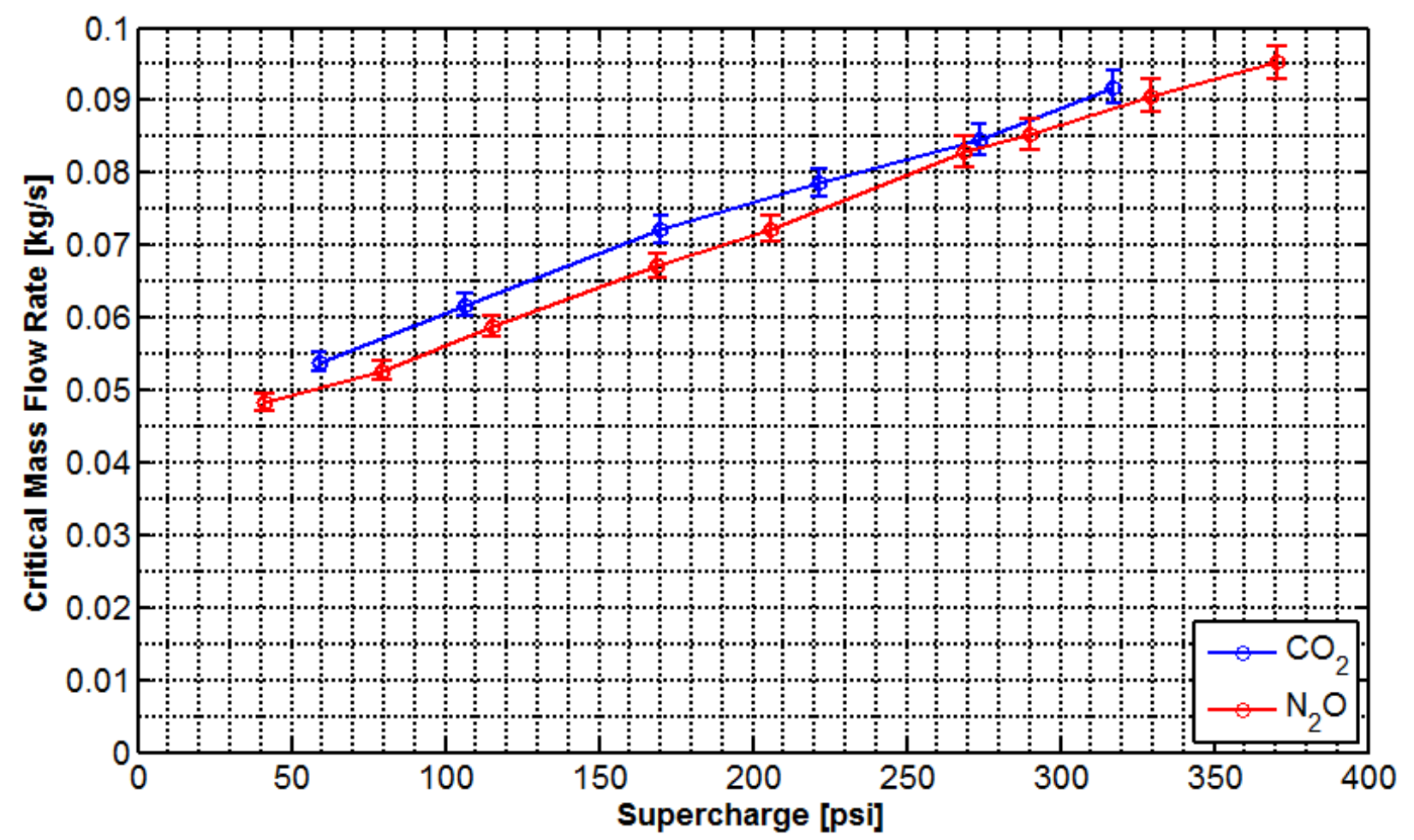

Figure 16. Critical mass flow rate vs. supercharge for injector number 3 using nitrous oxide and carbon dioxide.

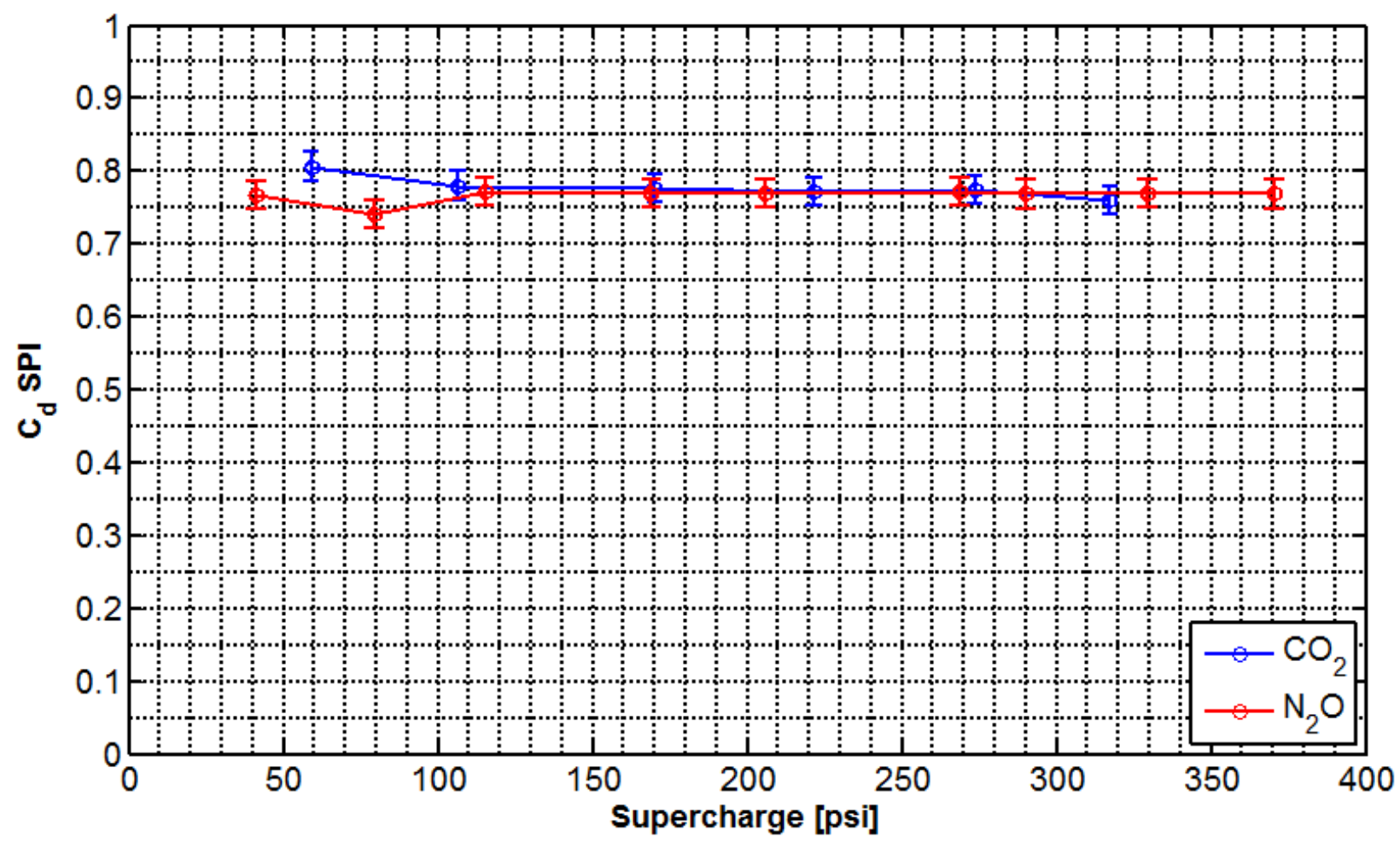

Figure 17. $C_{d}$ in the single-phase region vs. supercharge for injector number 3 using nitrous oxide and carbon dioxide. 


\section{Effect of Injector Hole Inlet Geometry}

The last mass flow rate characterization tests examine the effect of varying the orifice inlet geometry on the mass flow rate performance. These tests use carbon dioxide because it has been established that it is a good analog to nitrous oxide. The injectors used for this testing all have a minimum cross-sectional diameter of $1.5 \mathrm{~mm}$, but one has a square edged inlet, one is rounded, and the last has a chamfer (injectors number 2, 3, and 4 respectively). As with the previous analyses, we will compare the injector performance in the single-phase region and the two-phase region separately. Figure 18 shows the SPI discharge coefficient versus supercharge for the three different inlet geometries. It is clear from this plot that the square edged orifice exhibits a $C_{d}$ that is significantly lower than that of the rounded and chamfered injectors, which is expected. Additionally, the $C_{d}$ value for the rounded injector appears to be slightly higher than that of the chamfered injector; however the difference is less than the uncertainty in the measurement.

Figure 19 compares the critical mass flow rate of the same three injectors, and results in similar findings. The critical mass flow rate in the square edged injector is approximately $20 \%$ lower than that of the rounded and chamfered injector, which display nearly identical performance. In addition to serving as a useful design tool, Figure 18 and Figure 19 demonstrate a significant result: while the mass flow rate of an injector hole can be increased dramatically by installing a simple chamfer, there is almost no additional improvement by going through the extra effort to round the edges instead.

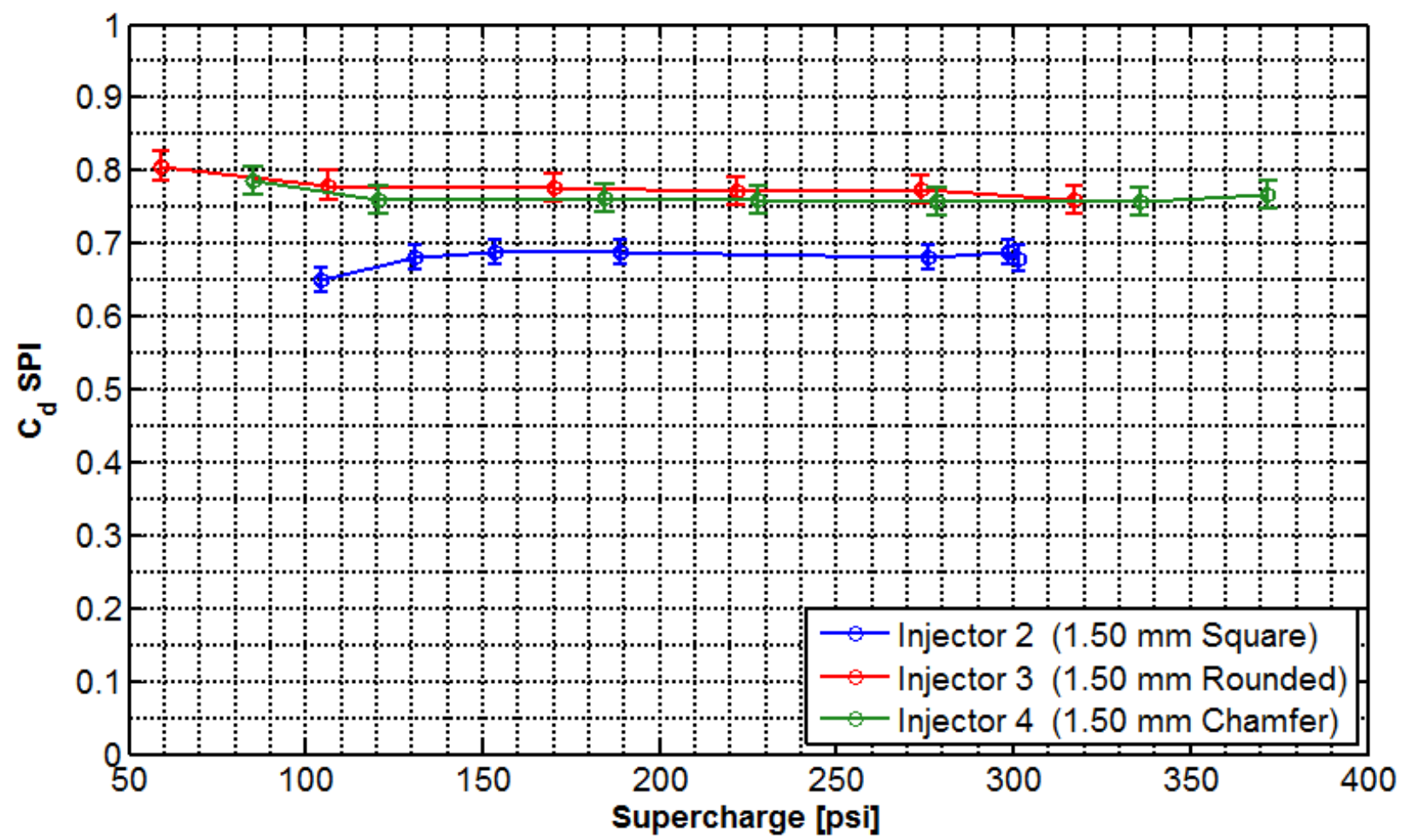

Figure 18. $C_{d}$ in the single-phase region vs. supercharge for injectors number 2,3 , and 4 using carbon dioxide. 


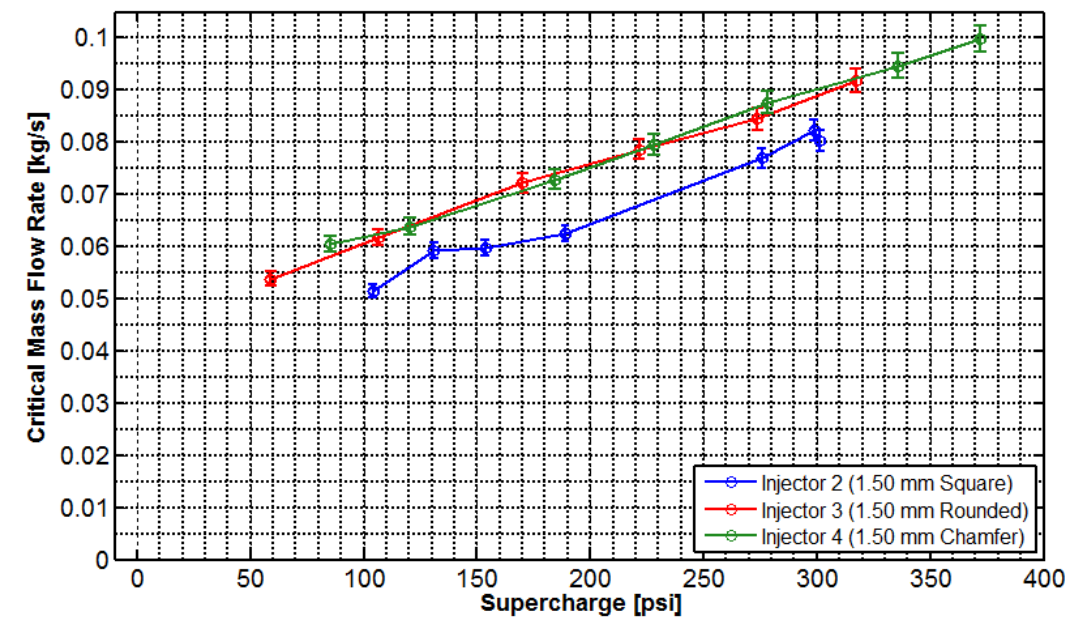

Figure 19. Critical mass flow rate vs. supercharge for injectors number 2,3 , and 4 using carbon dioxide.

\section{Comparison to the Dyer Model}

In order to validate the Dyer model as presented earlier in this work, the experimental and predicted critical mass flow rates are compared. Tests using each injector and both nitrous oxide and carbon dioxide have been included in these comparisons. Figure 20a shows the resulting comparison of the experimental critical mass flow rate to the Dyer model, when a $C_{d}$ value of 0.66 is used, as done in the work of Dyer et al. It can be seen that assuming a constant value of discharge coefficient results in reasonable agreement for a number of conditions, but a significant number of tests that lie outside of the region bounded by $\pm 10 \%$ error. However when the value of $C_{d}$ is allowed to vary by injector design ( 0.6 to 0.8 , determined based on the parameters known to effect the discharge coefficient, such as inlet geometry), the Dyer model does much better, as shown in Figure 20b. Not only are almost all of predicted critical values within $\pm 10 \%$ of the experimental values, but a majority lie within the $\pm 5 \%$ bounds. While these improvements are encouraging, there is still plenty of work to be done to improve our capabilities in the modeling of critical flow in self-pressurizing propellant injectors, and will be the focus of future work by the authors.

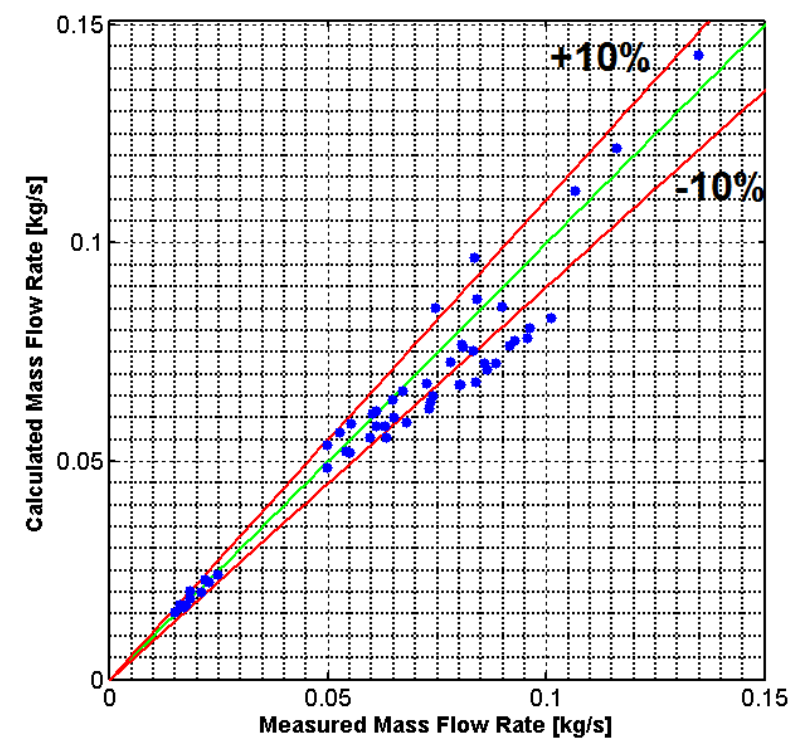

(a)

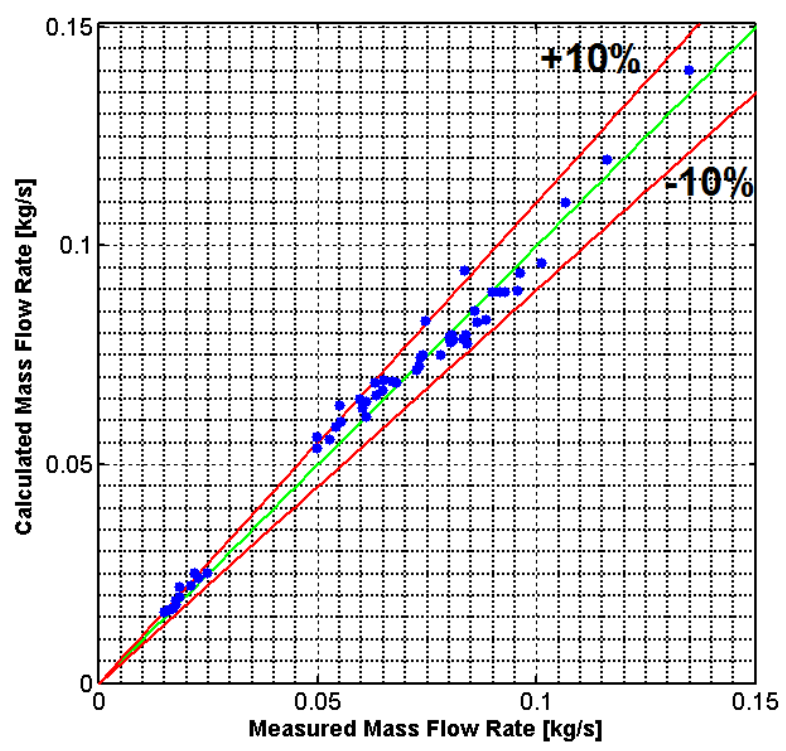

(b)

Figure 20. Comparison of experimental critical mass flow rate data to that predicted by the Dyer model. (a) $C_{d}=0.66$ (b) $C_{d}$ allowed to vary with injector inlet geometry. 


\section{Injector as an Isolating Element}

Combustion instability is one of the most commonly encountered problems in the development and testing of rocket propulsion systems, including hybrids. Large amplitude pressure oscillations often accompany combustion instabilities, resulting in increased vibrational loading, possible structural damage, and sometimes catastrophic system failure. Hybrid rocket instabilities can generally be split into two groups 1) high frequency (normally related to acoustics) and 2) low frequency (nonacoustic). Informally, the delineation between these groups is often located at approximately the frequency of the first longitudinal acoustic mode (1-L), with the 1-L mode included in the high frequency region (note that the 1-L frequency varies with combustion chamber geometry). Two different nonacoustic low frequency instabilities are often observed in hybrid rockets and receive the most attention. The first of these oscillatory behaviors is intrinsic to the interactions between turbulent boundary layer combustion and chamber fluid dynamic behavior. A detailed description of the intrinsic low frequency hybrid rocket instability is provided by Karabeyoglu et al. and is accompanied by the development of a model capable of predicting its frequency ${ }^{21}$. The second common low frequency response is known as feed coupled instability and will be discussed in the following sections.

\section{A. Feed System Coupled Instabilities}

Feed system coupled instabilities have been studied extensively in the liquid rocket industry, and have been successfully modeled for a range of engine designs and operating conditions ${ }^{22}$. These instabilities are typically characterized by highly regular, sinusoidal pressure oscillations which are caused by hydrodynamic communication between the combustion chamber and feed system, predominantly observed in systems utilizing liquid oxidizer. Work by Karabeyoglu et al. provides an overview of the feed coupled instability as it pertains to hybrid rockets, and describes a model for predicting its transient behavior ${ }^{23}$. As described in the aforementioned work, the mechanisms that contribute to feed system coupling are:

- Combustion and/or vaporization delay

- Oxidizer flow rate that is dependent on chamber pressure

- Compressibility of fluid in the feed system

The use of a properly designed injector can certainly be a factor in reducing the vaporization delay of oxidizer entering the combustion chamber. However, this work will focus on the mechanism that involves the oxidizer mass flow rate. As described in Section IIA, the mass flow rate of traditional oxidizers through the injector is usually dependent on both $P_{1}$ and $P_{2}$, the pressure upstream and downstream of the injector respectively. In order to achieve a mass flow rate that is independent of chamber pressure, an isolating element, such as a cavitating venturi is often placed in the feed system upstream of the injector. This has been shown to successfully minimize or completely eliminate feed system coupled instabilities in hybrid rockets ${ }^{24,25}$. For systems using nitrous oxide, it can be hazardous to operate with nitrous oxide vapor in the feed system upstream of the injector due to the increased likelihood for an explosive decomposition reaction. Therefore, the use of a cavitating venturi in the feed system is potentially problematic, and will not be considered here.

\section{B. Mass Flow Insensitivity to Chamber Pressure}

Fortunately, some of the mass flow rate studies presented earlier in this work identify a potential alternative to the cavitating venturi as a feed system isolating element. Recalling from Section IIB, when the pressure downstream of the injector falls sufficiently below the oxidizer vapor pressure, the mass flow rate not only reaches a maximum but becomes independent of the downstream pressure. It should be noted that this has been demonstrated for large values of orifice $L / D$, but is not expected to occur in thin plate orifices. Just as with the cavitating venturi, if the mass flow rate is "choked" by the injector element there is no longer a mechanism for coupling between the combustion chamber and the feed system. To assist in predicting the conditions necessary for this type of mass flow rate insensitivity, the data from Figure 13 in Section IV is reexamined. This time, mass flow rate is plotted against the ratio of downstream chamber pressure to the oxidizer saturation pressure $\left(P_{2} / P_{s}\right)$ in Figure 21. It is observed that chamber pressure disturbances occurring well below the vapor pressure of the oxidizer $\left(P_{2} / P_{s}\right.$ less than approximately 0.8$)$ should not be accompanied by any deviation in mass flow rate. As the chamber pressure disturbances approach but remain below the vapor pressure, the injector mass flow rate should start to become sensitive to changes in the chamber pressure, 
even though two-phase flow likely exists to some extent within the injector element. For chamber pressures above the saturation pressure of the oxidizer, single-phase flow is expected and pressure disturbances in the chamber should be reflected in the injector mass flow rate as predicted by the single-phase incompressible equation.

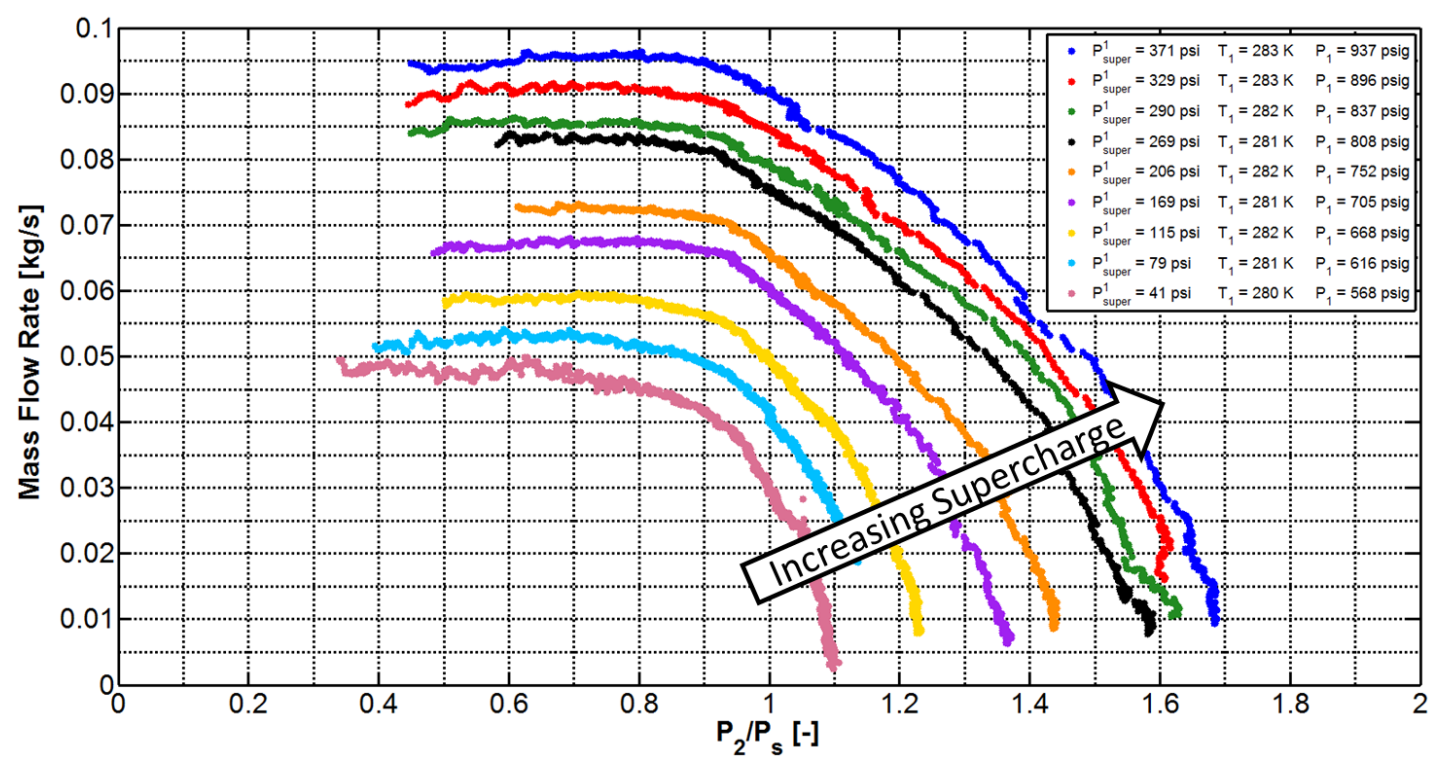

Figure 21. Mass flow rate vs. the ratio of chamber pressure to oxidizer saturation pressure $\left(P_{2} / P_{s}\right)$.

In order to verify the behavior outlined above and test the ability of an injector orifice to provide mass flow insensitivity in more realistic dynamic operation, the experimental test apparatus described in Section IIIA was adapted to allow for rapid pressurization and depressurization of the downstream section in an oscillatory fashion. Pressurization was achieved by introducing a source of high pressure nitrogen, up to $2600 \mathrm{psig}$ (18.0 MPa), that could be supplied to the downstream test section through a variable speed rapidly actuated motor driven ball valve. In order to allow for rapid depressurization, the downstream chamber was also connected to a large backpressure regulator $\left(C_{v}=3.0\right)$ which vents to the atmosphere. With high pressure nitrogen supplied periodically to the test section, and the backpressure regulator relieving the corresponding backpressure buildup, simulated chamber pressure oscillations were achieved with peak-to-peak amplitudes up to $200 \mathrm{psi}(1.38 \mathrm{MPa})$ and at frequencies of up to $50 \mathrm{~Hz}$. By varying the regulator pressure of the nitrogen supply and the set pressure of the backpressure regulator, the peak-to-peak amplitude and the mean pressure of the oscillations could be shifted up or down to the desired level for a test.

A series of tests were performed with carbon dioxide in order examine the injector mass flow rate response to downstream oscillations at three different chamber pressure levels, with the results shown in Figure 22 and Figure 23. Injector number 2 was used for all of these tests, which flow carbon dioxide at room temperature (approximately $T_{1}=$ $293 \mathrm{~K}$ ). In order to most clearly present the results, data from all three tests are presented side by side in the same scale. Figure 22 shows the pressure time histories for each of the three tests, and the corresponding mass flow rate responses are shown directly below for each test in Figure 23. Moving left to right from Test 1 to Test 3, it can be observed that the upstream pressure $P_{1}$ and the saturation pressure $P_{s}$ are held relatively constant among the tests, while the average of the downstream pressure oscillations is increased. Figure 22a shows the pressure time histories for Test 1, during which the chamber pressure is well below the saturation pressure $\left(P_{2 \text { avg }} / P_{s}=0.78\right)$. Figure 23a below it shows the mass flow rate data for the same test, and it is clear that the response is insensitive to the downstream pressure. Moving to the right, Figure 22b shows Test 2, where the chamber pressure is still below, but very close to the vapor pressure $\left(P_{2 \text { avg }} / P_{s}=0.93\right)$. As described earlier in this section, even though it is likely that there is vapor formation within the injector, the mass flow rate is still sensitive to the downstream pressure, and this is reflected in the response plotted in Figure 23b. Finally, moving to Figure 22c and Figure 23c, the mass flow rate is highly sensitive to the downstream pressure as it rises above the saturation pressure $\left(P_{2 \text { avg }} / P_{s}=1.03\right)$, as is to be expected. A summary of some of the important test data can be found in Table 3 . 


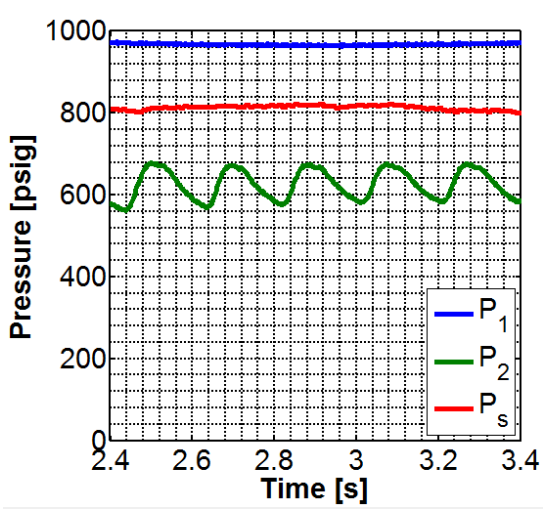

(a)

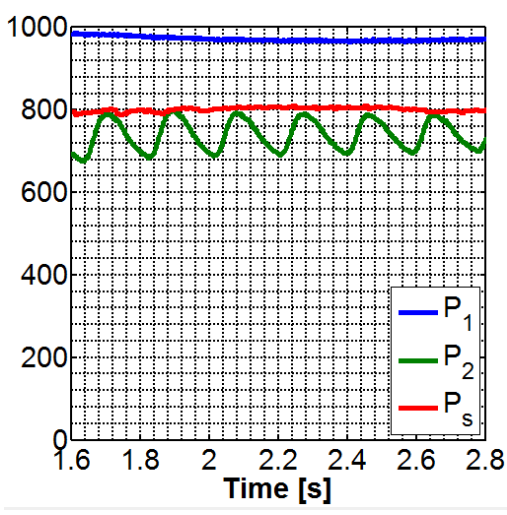

(b)

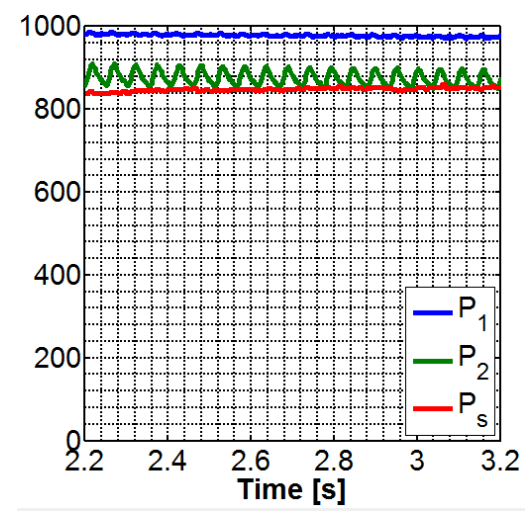

(c)

Figure 22. Pressure time histories for oscillatory tests: (a) Test 1, (b) Test 2 and (c) Test 3. All tests used injector number 2 with carbon dioxide at a temperature of approximately $T_{1}=293 \mathrm{~K}$.

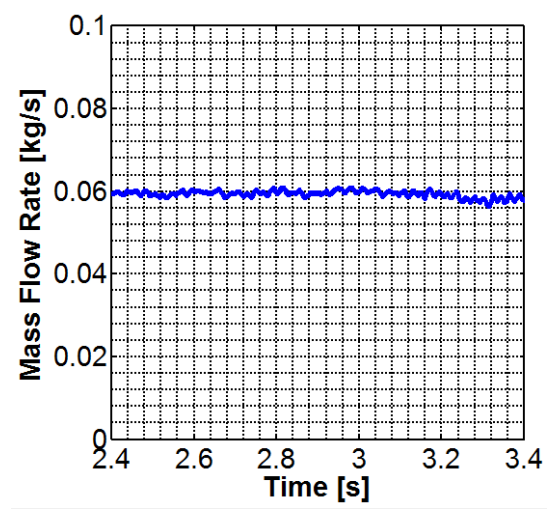

(a)

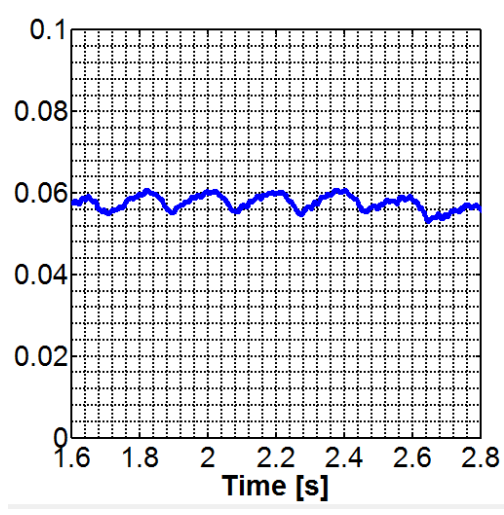

(b)

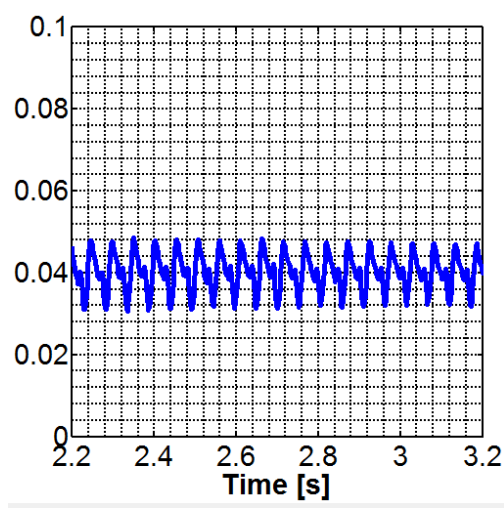

(c)

Figure 23. Mass flow rate data for oscillatory tests: (a) Test 1, (b) Test 2 and (c) Test 3. All tests used injector number 2 with carbon dioxide at a temperature of approximately $T_{1}=293 \mathrm{~K}$.

While the above plots do suggest that the transition to "choked" injector response occurs as the chamber pressure drops below the oxidizer saturation pressure, it is important to prove that the transition is not merely dependent on the injector pressure drop. In order to perform this evaluation, two tests were performed at nearly identical pressure drops and oscillation characteristics, as shown in Figure 24 with the resulting mass flow repose shown in Figure 25. These tests were also performed with carbon dioxide using injector number 2 . The only difference between these two tests was the temperature of the oxidizer. The oxidizer temperature was varied in order to shift the saturation pressure from test to test. Figure 26 shows the saturation pressure of carbon dioxide over a range of temperatures. The temperature of the first test was approximately $T_{1}=293 \mathrm{~K}$, and the temperature of the second test was approximately $T_{1}=260 \mathrm{~K}$ (corresponding to Tests 4 and 5 respectively). These temperatures correspond to saturation pressures of 830 psia (5.72 $\mathrm{MPa}$ ) in Test 4 and $355 \mathrm{psia}(2.45 \mathrm{MPa})$ in Test 5 . More details of the test data can be found in Table 3 . We are now able to compare the mass flow rate performance between the two tests without the effect of changing the pressure drop $\Delta P$. Figure 24a and Figure 25a from Test 4 show the insensitivity of mass flow rate to downstream pressure compared to that of Test 5 shown in Figure 24b and Figure 25b. In fact, the peak-to-peak amplitude of the mass flow rate response is increased by approximately 700 percent just by cooling the carbon dioxide and shifting the vapor pressure below the downstream oscillation pressure. These results confirm our earlier description of the mechanism resulting in mass flow rate insensitivity. Also of note, the mass flow rate in Test 5 is approximately 50 percent higher than in Test 4. This can be explained by 2 effects. First, the density of carbon dioxide decreases with increasing temperature, and the 
carbon dioxide used in Test 5 was significantly colder than in Test 4. More importantly, the mass flow rate in Test 4 is limited by the onset of vapor formation and critical flow, while in Test 5 the carbon dioxide is still all liquid and the mass flow can continue to increase. It should be noted that the mass flow rate profiles do not share the exact same character as the pressure oscillations for these tests. This is due to some electromagnetic interference caused by the "noisy" electrical motor driving the ball valve during the experiments. This effect has been verified over a range of operating conditions and work is currently being performed to further shield the mass flow rate instrumentation and wiring in order to produce higher quality measurements.

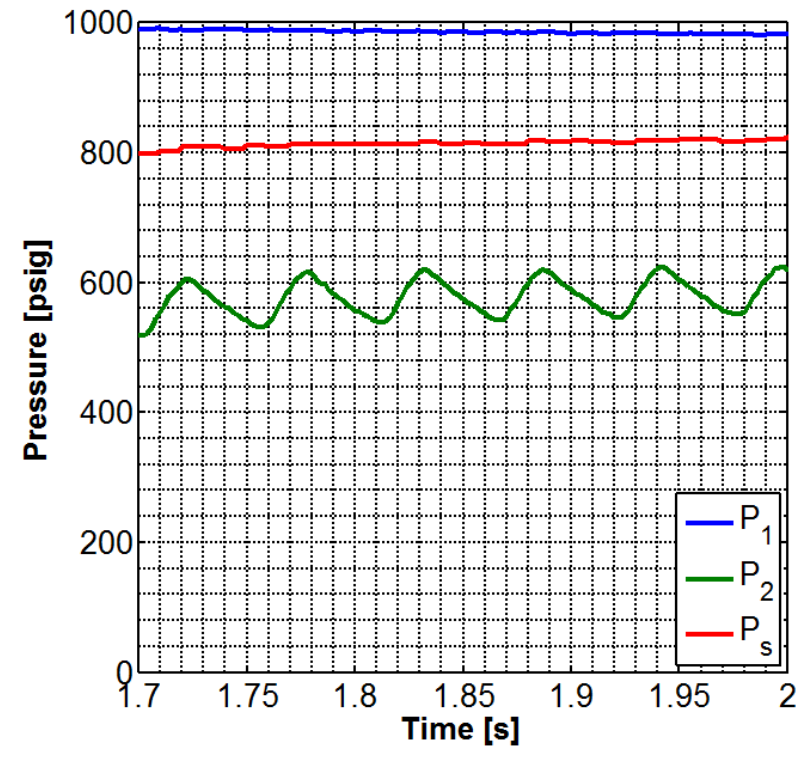

(a)

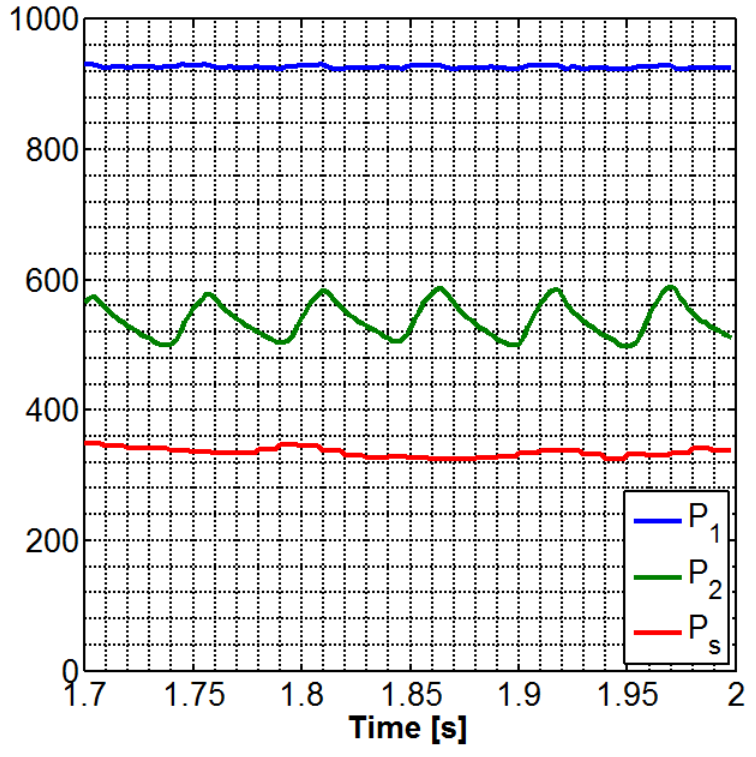

(b)

Figure 24. Pressure time histories for oscillatory tests: (a) Test 4 and (b) Test 5 . Both tests used injector number 2 with carbon dioxide at temperatures of approximately (a) $T_{1}=293 \mathrm{~K}$ and (b) $T_{1}=260 \mathrm{~K}$.

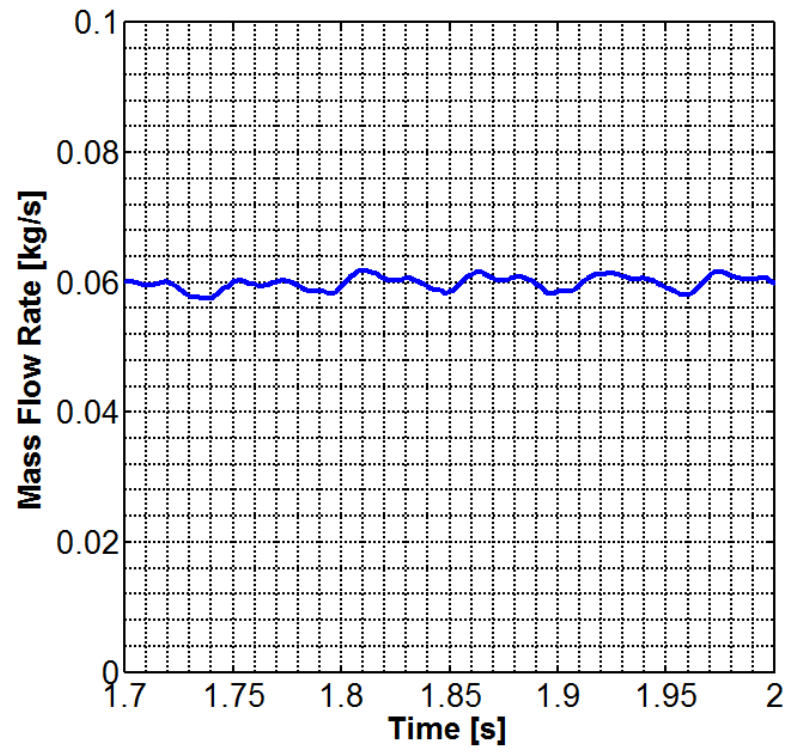

(a)

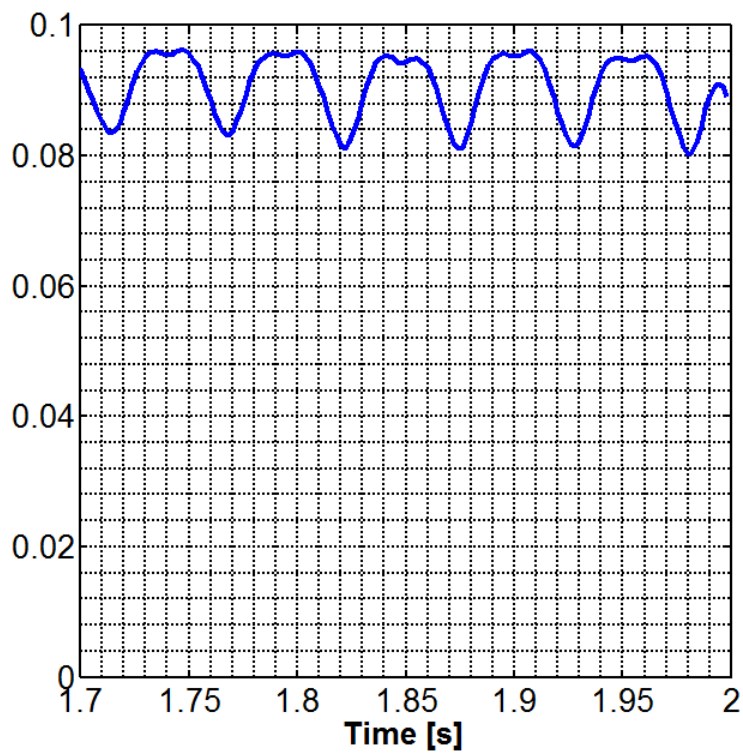

(b)

Figure 25. Mass flow rate data for oscillatory tests: (a) Test 4 and (b) Test 5. Both tests used injector number 2 with carbon dioxide at temperatures of approximately (a) $T_{1}=293 \mathrm{~K}$ and (b) $T_{1}=260 \mathrm{~K}$. 


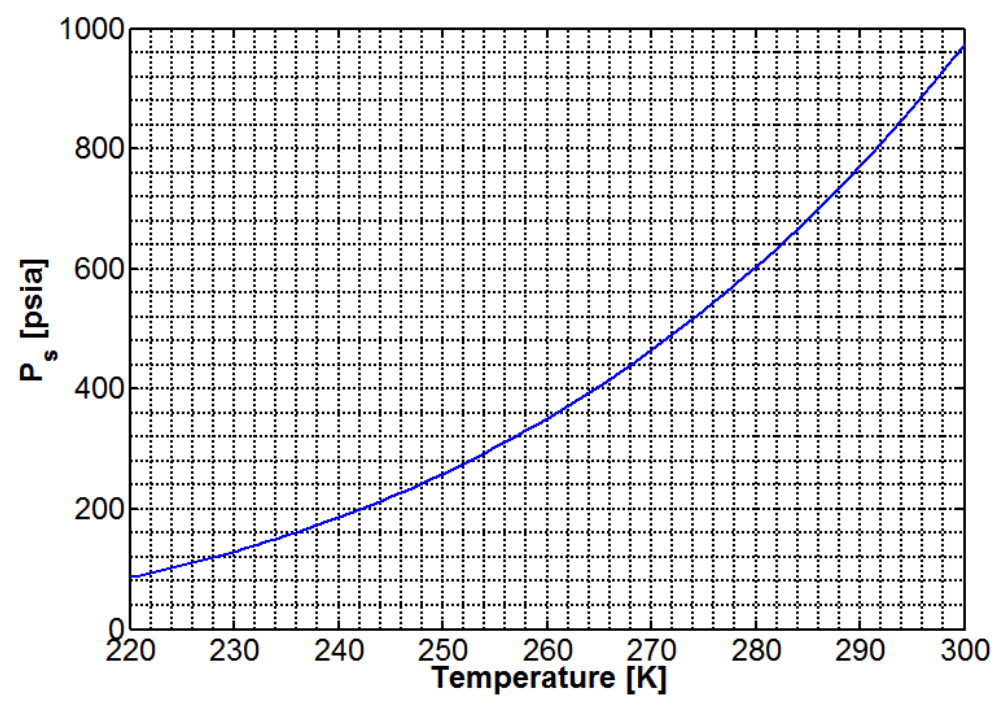

Figure 26. Saturation pressure $P_{s}$ vs. temperature for carbon dioxide.

Table 3. Oscillatory Test Data Summary

\begin{tabular}{ccccccccc}
\hline Test & $\begin{array}{c}P_{1_{\text {avg }}} \\
\mathrm{psia}(\mathrm{MPa})\end{array}$ & $\begin{array}{c}P_{2 \text { avg }} \\
\mathrm{psia}(\mathrm{MPa})\end{array}$ & $\begin{array}{c}P_{2 p k-p k} \\
\mathrm{psi}(\mathrm{MPa})\end{array}$ & $\begin{array}{c}P_{s} \\
\mathrm{psia}(\mathrm{MPa})\end{array}$ & $P_{2 \text { avg }} / P_{s}$ & $\begin{array}{c}\text { Frequency } \\
(\mathrm{Hz})\end{array}$ & $\begin{array}{c}\dot{m}_{\text {avg }} \\
(\mathrm{kg} / \mathrm{s})\end{array}$ & $\begin{array}{c}\dot{m}_{p k-p k} \\
(\mathrm{~kg} / \mathrm{s})\end{array}$ \\
\hline \hline 1 & $984(6.78)$ & $641(4.42)$ & $125(0.862)$ & $827(5.70)$ & 0.78 & 5 & 0.059 & 0.001 \\
\hline 2 & $988(6.81)$ & $756(5.21)$ & $100(0.689)$ & $816(5.63)$ & 0.93 & 5 & 0.057 & 0.005 \\
\hline 3 & $994(6.85)$ & $892(6.15)$ & $70(0.483)$ & $863(5.95)$ & 1.03 & 19 & 0.040 & 0.020 \\
\hline 4 & $999(6.89)$ & $590(4.07)$ & $90(0.621)$ & $830(5.72)$ & 0.71 & 18 & 0.060 & 0.002 \\
\hline 5 & $940(6.48)$ & $555(3.83)$ & $85(0.586)$ & $355(2.45)$ & 1.56 & 18 & 0.089 & 0.014 \\
\hline
\end{tabular}

\section{Pressure Disturbance Isolation}

Section VB has shown that critical flow injectors can potentially be used as a means of improving combustion stability by eliminating the dependance of mass flow rate on the downstream chamber pressure. However, in order to achieve stable, controlled combustion, it is also important to isolate the feed system from acoustic propagation of pressure disturbances from the combustion chamber back through the injector. Pressure oscillations associated with combustion instabilities have been observed to transmit from the combustion chamber to the feed system in the development of hybrid rockets, particularly when purely liquid oxidizer is expected to be flowing through the injector ${ }^{26}$. However, it has been shown throughout the literature that the introduction of two-phase flow often results in the attenuation of acoustic pressure waves and shock waves due to increased compressibility as well as interfacial phase boundary interactions ${ }^{27}$. Therefore, the presence of two-phase flow in a hybrid rocket injector element provides the potential for isolation of pressure oscillations being transmitted back to the feed system.

In order to evaluate the effectiveness of pressure wave attenuation in two-phase flow injectors, we will again examine some of the oscillatory test data presented in Section VB. Figure 27 shows the same pressure time histories as seen in Figure 22, however the range of pressures on each of the plots was narrowed to allow for better visibility of small fluctuations in $P_{1}$. It is immediately clear that of the three tests presented, only Test 3 shown in Figure 27c exhibits any noticeable pressure oscillations upstream of the injector (signaling a lack of isolation). This result does not necessarily mean that two-phase flow is necessary for isolation, or that no attenuation occurs with single-phase flow. However, it does confirm that two-phase flow is more effective at providing attenuation than single-phase liquid 
flow. Neither Test 1 nor Test 2 (Figure 27a and Figure 27b respectively) show any visible oscillations in the $P_{1}$ pressure signal. It is important to note that even though Test 2 does not operate in the critical flow regime, some vapor formation is expected, and these results show that sufficient isolation is still achieved.

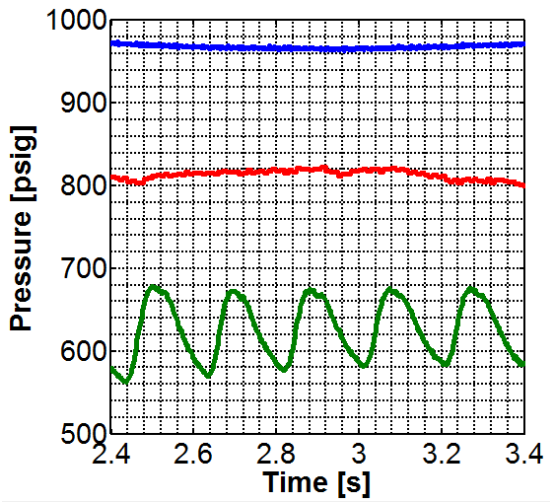

(a)

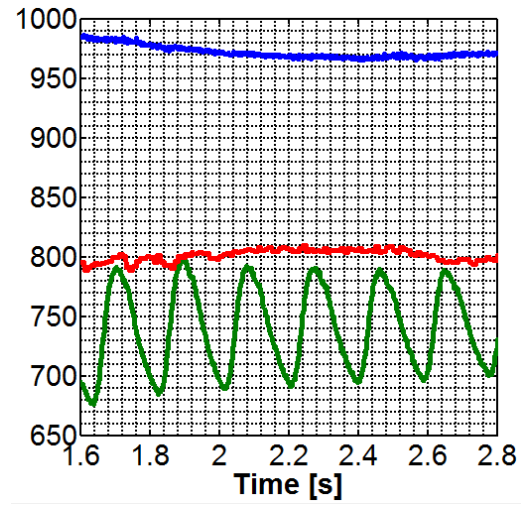

(b)

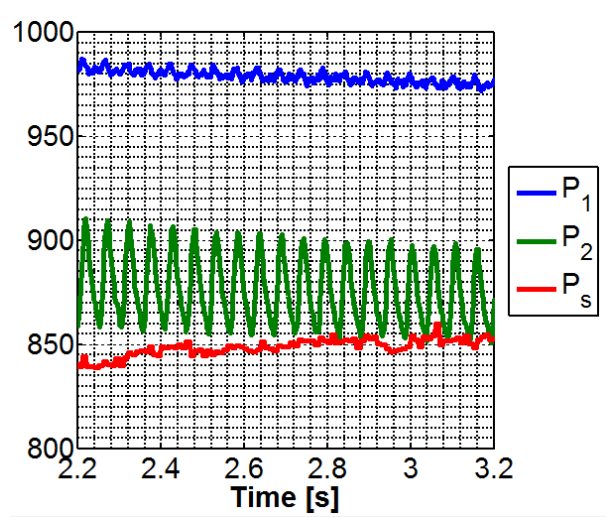

(c)

Figure 27. Pressure time histories for oscillatory tests: (a) Test 1, (b) Test 2 and (c) Test 3. All tests used injector number 2 with carbon dioxide at a temperature of approximately $T_{1}=293 \mathrm{~K}$. Zoomed in for examination of oscillations in $P_{1}$ signal.

The results presented in this section are encouraging in that a properly designed injection scheme could provide the necessary pressure disturbance attenuation to allow for well controlled, stable combustion. However, a complete study of the attenuation dependance on operating conditions and injector geometry has not been completed, but is currently underway. Additionally, it has been shown in the literature that the attenuation level of acoustic waves can be dependent on the frequency of the oscillations ${ }^{27}$. This effect will be studied in future work with the test apparatus.

\section{Summary and Conclusions}

This work has described the experimental testing of hybrid rocket injectors for use with self-pressurizing propellants, specifically nitrous oxide. This paper was split into four parts:

1. A background into the commonly used methods for predicting hybrid rocket injector mass flow rate was included. The lack of reliable discharge coefficient data or extensive validation for these models was used to provide a motivation for the experimental work.

2. A description of the test facility and the test method for making mass flow rate measurements was provided. Due to safety concerns, a discussion of the use of carbon dioxide as an analog to nitrous oxide was presented.

3. Initial experimental results were presented and compared to the aforementioned models to within 5-10\%. The variations in performance for different injector designs and fluids were compared as outlined below:

- $C_{d}$ in the single-phase region is inversely proportional to injector hole diameter.

- Critical flow occurs when the chamber pressure falls sufficiently below the oxidizer saturation pressure.

- Mass flow rate is enhanced by rounding or chamfering the inlet for both the single-phase and two-phase regions, however almost no improvement is seen by switching from chamfered to rounded.

- Validity of using carbon dioxide as an analog to nitrous oxide was confirmed.

4. An experimental demonstration highlighted the potential viability of using the injector as an isolating element in order to prevent the occurrence of feed system coupled combustion instabilities in hybrid rockets as described below: 
- Critical two-phase flow in the injector was proven to be effective in ensuring that the mass flow rate is insensitive to dynamic changes in downstream pressure. For simple orifice style injectors, mass flow rate insensitivity can generally be expected when the chamber pressure $P_{2}$ is less then $80 \%$ of the oxidizer saturation pressure $P_{s}$

- Feed system isolation from downstream acoustic pressure disturbances was shown to be effective when two-phase flow exists within the injector, even when operating outside of the critical regime.

\section{Future Work}

The data from this work will be compiled into a database and a user interface will be developed to assist in hybrid rocket injector design. Injector mass flow rate and isolation performance characterization is ongoing and will investigate the effects of the following:

- Injector length

- Injector length to diameter ratio

- Angled holes

- Helium desorption

- Unconventional hole geometry

- Dependance on disturbance frequency

The results from these tests will be leveraged in an attempt to eliminate feed coupled combustion instabilities from hybrid rockets currently under development. Additionally, various commercial CFD packages will be assessed for their accuracy in predicting both the single-phase incompressible discharge coefficient and the transition to critical "choked" flow.

\section{Acknowledgments}

This work was supported in part by the National Defense Science and Engineering Graduate Fellowship Program (NDSEG) as well as NASA Ames Research Center, and the Aeronautics and Astronautics Department at Stanford University. Portions of this work were funded under NASA Space Technology Research Grant \#NNX11AN14H. The authors would like to thank Jeremy Corpening of Teledyne Brown Engineering and Harry Ryan of NASA Stennis Space Center for their assistance and David Murakami, Chris Zaseck, and Javier Stober for assisting in the test campaign.

\section{References}

${ }^{1}$ Dyer, J., Doran, E., Dunn, Z., Lohner, K., Bayart, C., Sadhwani, A., Cantwell, B., and Karabeyoglu, A., "Design and Development of a 100 km Nitrous Oxide / Paraffin Hybrid Rocket Vehicle," 43rd AIAA/ASME/SAE/ASEE Joint Propulsion Conference and Exhibit, Cincinnati, OH, July 2007.

${ }^{2}$ Thicksten, Z., Macklin, F., and Campbell, J., "Handling Considerations of Nitrous Oxide in Hybrid Rocket Motor Testing," 44th AIAA/ASME/SAE/ASEE Joint Propulsion Conference and Exhibit, Hartford, CT, July 2008.

${ }^{3}$ Waxman, B. S., Cantwell, B. J., and Zilliac, G., "Effects of Injector Design and Impingement Techniques on the Atomization of SelfPressurizing Oxidizers," 48th AIAA/ASME/SAE/ASEE Joint Propulsion Conference and Exhibit, Atlanta, GA, Aug. 2012.

${ }^{4}$ Waxman, B. S., Zimmerman, J. E., Cantwell, B. J., and Zilliac, G. G., "Mass Flow Rate Characterization of Injectors for Use with SelfPressurizing Oxidizers in Hybrid Rockets," 60th Joint Army-Navy-NASA-Air Force (JANNAF) Propulsion Meeting, Colorado Springs, CO, May 2013, p. Available via email by contacting waxman@stanford.

${ }^{5}$ Sutton, G. and Biblarz, O., Rocket Propulsion Elements, Wiley and Sons, New York, 7th ed., 2001.

${ }^{6}$ Lemmon, E. W., Huber, M., and McLindon, M., "NIST Standard Reference Database 23: Reference Fluid Thermodynamic and Transport Properties-REFPROP, Version 930," 2010.

${ }^{7}$ Lemmon, E. W. and Span, R., "Short Fundamental Equations of State for 20 Industrial Fluids," Journal of Chemical Engineering Data, Vol. 51, 2006, pp. 785-850.

${ }^{8}$ Dyer, J., Doran, E., Dunn, Z., Lohner, K., and Zilliac, G., "Modeling Feed System Flow Physics for Self-Pressurizing Propellants," 43rd AIAA/ASME/SAE/ASEE Joint Propulsion Conference and Exhibit, Cincinnati, OH, July 2007. 
${ }^{9}$ Hesson, J. and Peck, R., "Flow of Two-phase Carbon Dioxide Through Orifices," AIChE Journal, Vol. 4, No. 2, 1958, pp. $207-210$.

${ }^{10}$ Henry, R. E. and Fauske, H. K., "The Two-Phase Critical Flow of One-Component Mixtures in Nozzles , Orifices , and Short Tubes," Journal of Heat Transfer, May 1971, pp. 179-187.

${ }^{11}$ Leung, J., "A Generalized Correlation for One-component Homogeneous Equilibrium Flashing Choked Flow," AIChE Journal, Vol. 32 , No. 10 , Oct. 1986 , pp. 1743-1746.

${ }^{12}$ Leung, J. C. and Grolmes, M. A., "A Generalized Correlation for Flashing Choked Flow of Initially Subcooled Liquid," AIChE Journal, Vol. 34, No. 4, April 1988, pp. 688-691.

${ }^{13}$ Solomon, B. J., Engineering Model to Calculate Mass Flow Rate of a Two-Phase Saturated Fluid Through An Injector Orifice, Masters thesis, Utah State University, 2011.

${ }^{14}$ Zimmerman, J. E., Cantwell, B., and Zilliac, G., "Initial Experimental Investigations of Self-Pressurizing Propellant Dynamics," 48th AIAA/ASME/SAE/ASEE Joint Propulsion Conference and Exhibit, Atlanta, GA, Aug. 2012.

${ }^{15}$ Zimmerman, J. E., Waxman, B. S., Cantwell, B. J., and Zilliac, G. G., "Comparison of Nitrous Oxide and Carbon Dioxide with Applications to Self-Pressurizing Propellant Tank Expulsion Dynamics," 60th Joint Army-Navy-NASA-Air Force (JANNAF) Propulsion Meeting, Colorado Springs, CO, May 2013.

${ }^{16}$ Cawthra, J. and Eisenstadt, M., "Summary of Nitrous Oxide Investigations," TR-75-231, July 1974, pp. 10-16.

${ }^{17}$ Karabeyoglu, A., Dyer, J., Stevens, J., and Cantwell, B., "Modeling of N2O Decomposition Events," 44th AIAA/ASME/SAE/ASEE Joint Propulsion Conference and Exhibit, Hartford, CT, July 2008.

${ }^{18}$ Wark, K. J., Advanced Thermodynamics for Engineers, McGraw-Hill, New York, 1995.

${ }^{19}$ Span, R. and Wagner, W., "A New Equation of State for Carbon Dioxide Covering the Fluid Region from the Triple-Point Temperature to $1100 \mathrm{~K}$ at Pressures up to 800 MPa," Journal of Physical and Chemical Reference Data, Vol. 25, No. 6, 1996, pp. 1509-1596.

${ }^{20}$ Shallcross, D., "Humidity Diagrams for Engineers," Physical Property Data, Handbook of Psychrometric Charts, p. 20.

${ }^{21}$ Karabeyoglu, M. A., Zilwa, S. D., Cantwell, B., and Zilliac, G., "Transient Modeling of Hybrid Rocket Low Frequency Instabilities," 39th AIAA/ASME/SAE/ASEE Joint Propulsion Conference and Exhibit, July 2003.

${ }^{22}$ Yang, V. and Anderson, W., "Liquid Rocket Engine Combustion Instability," Progress in Astronautics and Aeronautics, Vol. $169,1995$.

${ }^{23}$ Karabeyoglu, A., Stevens, J., and Cantwell, B., "Investigation of Feed System Coupled Low Frequency Combustion Instabilities in Hybrid Rockets," 43rd AIAA/ASME/SAE/ASEE Joint Propulsion Conference and Exhibit, No. July, Cincinnati, OH, July 2007.

${ }^{24}$ Carpenter, R. L., Boardman, T. A., and Claflin, S. E., "Hybrid Propulsion for Launch Vehicle Boosters : A Program Status Update," 31 st AIAA / ASME / SAE / ASEE Joint Propulsion Conference and Exhibit, San Diego, CA, July 1995.

${ }^{25}$ Rocker, M., "Modeling of Nonacoustic Combustion of Hybrid Instability in Simulations Motor Tests," Tech. rep., NASA, 2000.

${ }^{26}$ Zilliac, G., Waxman, B. S., Doran, E., Dyer, J., Karabeyoglu, M. A., and Cantwell, B., "Peregrine Hybrid Rocket Motor Ground Test Results," 48th AIAA/ASME/SAE/ASEE Joint Propulsion Conference and Exhibit, Atlanta, GA, Aug. 2012.

${ }^{27}$ Brennen, C., Fundamentals of Multiphase Flows, 2005.

${ }^{28}$ Perry, R. and Green, D., Perry's Chemical Engineers' Handbook, McGraw-Hill, 6th ed., 1984.

${ }^{29}$ Cornelius, K. C. and Srinivas, K., “Isentropic Compressible Flow for Non-Ideal Gas Models for a Venturi," Journal of Fluids Engineering, Vol. 126, No. 2, March 2004, pp. 238-244.

${ }^{30}$ Lienhard, J. H. and Karimi, A., "Homogeneous Nucleation and the Spinodal Line," Journal of Heat Transfer, Vol. 103, No. 1, Feb. 1981, pp. 61-64.

${ }^{31}$ Shamsundar, N. and Lienhard, J. H., "Equations of State and Spinodal Lines - A Review," Nuclear Engineering and Design Journal, Vol. 141, No. 1, 1993, pp. 269-287. 


\section{A. Compressibility Effects}

To account for compressibility effects, a compressibility correction factor, $Y$, can be introduced as in Eqn. (11).

$$
\dot{m}=C_{d} Y A \sqrt{2 \rho \Delta P}
$$

For ideal gases, the compressibility correction factor is well known and can be found in handbooks such as that of Perry and Green ${ }^{28}$. However, for compressible liquids, the correction factor should be calculated in the same fashion as that of Zimmerman et al. ${ }^{14}$ In that work, the correction factor was calculated for venturi flow rate measurements of nitrous oxide, which are also governed by Eqn. (11). This form of the compressible liquid correction factor, $Y^{\prime}$, is outlined in Eqn. (12) and Eqn. (13) and is also valid for injectors, but only under the assumption of isentropic flow through the orifice:

$$
\begin{gathered}
Y^{\prime}=\sqrt{\frac{P_{t}}{2 \Delta P}\left(\frac{2 n}{n-1}\right)\left(1-\frac{\Delta P}{P_{t}}\right)^{\frac{2}{n}}\left[1-\left(1-\frac{\Delta P}{P_{t}}\right)^{\frac{n-1}{n}}\right]} \\
n=\gamma\left[\frac{Z+T\left(\frac{\partial Z}{\partial T}\right)_{\rho}}{Z+T\left(\frac{\partial Z}{\partial T}\right)_{P}}\right]
\end{gathered}
$$

where $P_{t}$ is the upstream stagnation pressure, and $\mathrm{n}$ is the isentropic power law exponent as defined by Cornelius and Srinivas ${ }^{29}$. When $A \ll A_{1}$, the upstream pressure $P_{1}$ can be used for $P_{t}$. As long as an appropriate method for calculating $Z$ exists (e.g. highly accurate equations of state exist for nitrous oxide which have been programmed by the National Institute of Standards and Technology in the user friendly REFPROP computer program ${ }^{6,7}$ ), the above equations can be applied to nitrous oxide as it can be described by the real gas equation of state shown in Eqn. $(14)^{14}$ :

$$
P=Z \rho R T
$$

where $R$ is the specific gas constant. Zimmerman et al. concluded that in flow venturis, where the value of $\Delta P$ is generally small $(<50 \mathrm{psi})$, the effects of compressibility can be negligible under certain conditions. However, injectors often establish very large pressure drops ( $\gg 50 \mathrm{psi}$ ), and therefore $Y^{\prime}$ may deviate significantly from unity. Figure 28 shows the compressible liquid correction factor as calculated for nitrous oxide at an upstream pressure of $1000 \mathrm{psia}$ over a range of temperatures. As the nitrous oxide approaches the critical temperature $(309.5 \mathrm{~K})$ and the compressibility increases, the compressible liquid correction factor becomes more important. At low values of $\Delta P$, the effect is always small as expected, however as $\Delta P$ increases, so too does the importance of accounting for compressibility. While the use of a compressibility correction can provide improved accuracy of the " $C_{d} A$ " equation for single-phase liquid nitrous oxide injectors, of greater concern is the onset of two-phase flow. As has been shown, at the highest $\Delta P$ values in Figure 28, the effects of two-phase flow within the injector element overshadow the effects of compressibility, thus rendering the classical form of the " $C_{d} A$ " equation unsuitable for high vapor pressure propellants such as nitrous oxide. 


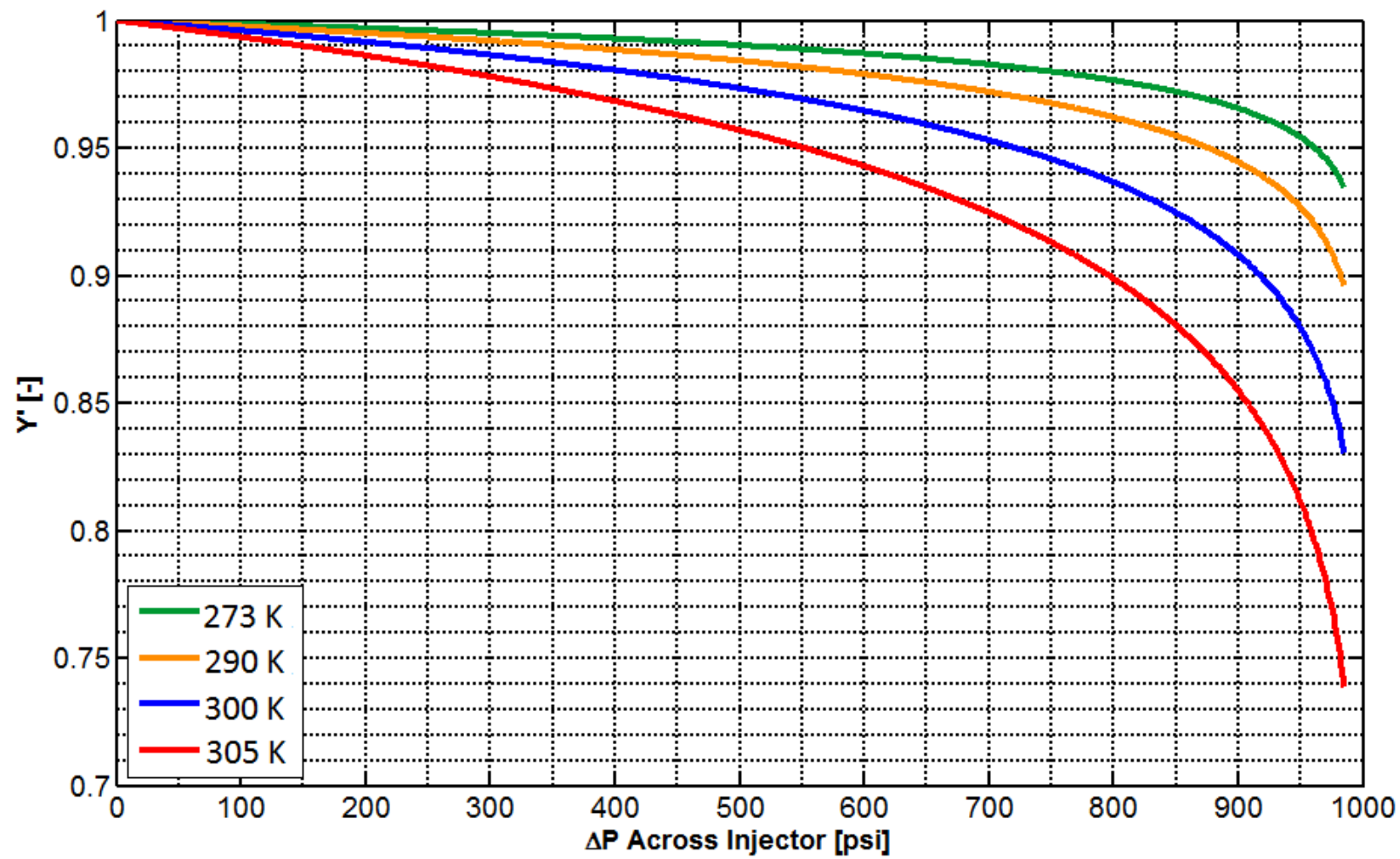

Figure 28. Compressible liquid correction factor vs. $\Delta P$ across the injector for $P_{1}=1000$ psia over a range of nitrous oxide temperatures $\left(T_{c}=309.5 \mathrm{~K}\right)$. The data used to produce this plot was calculated using REFPROP ${ }^{6,7}$. 


\section{B. Metastable States}

The extent to which the liquid can theoretically be superheated in the metastable state is bounded by the liquid spinodal line. The spinodal lines mark the limits of the region where only unstable fluid can exist, therefore homogeneous nucleation must occur at some point before reaching the spinodal line ${ }^{30}$. Thus, the metastable region is located between the saturation line and the spinodal line, which is depicted graphically by the purple region in Figure 29. The spinodal lines can be calculated by following the traverse of the outermost isothermal local extrema (i.e. the extrema closest to the saturation curves). Specifically, the liquid and vapor spinodal lines are collocated with the outermost isothermal local minima and maxima respectively, and they meet at the thermodynamic critical point. The ability of the metastable liquid to approach the spinodal limit is dependent upon a variety of factors, including the rate of depressurization, availability of nucleation sites, and the level of disturbances that would tend to cause heterogeneous nucleation and flashing to vapor ${ }^{30,31}$. Depending on the rate of depressurization, the liquid follows a process bounded by the isentropic and isothermal curves as shown in Figure 29. The isentropic path corresponds to an infinitely fast depressurization and the isothermal line corresponds to an extremely slow process, whereas an actual fluid trajectory will lie somewhere between the two ${ }^{31}$. The variability of this process is reflected in experimental measurements of the onset of the critical flow regime, and the modeling of this phenomenon is an ongoing area of research.

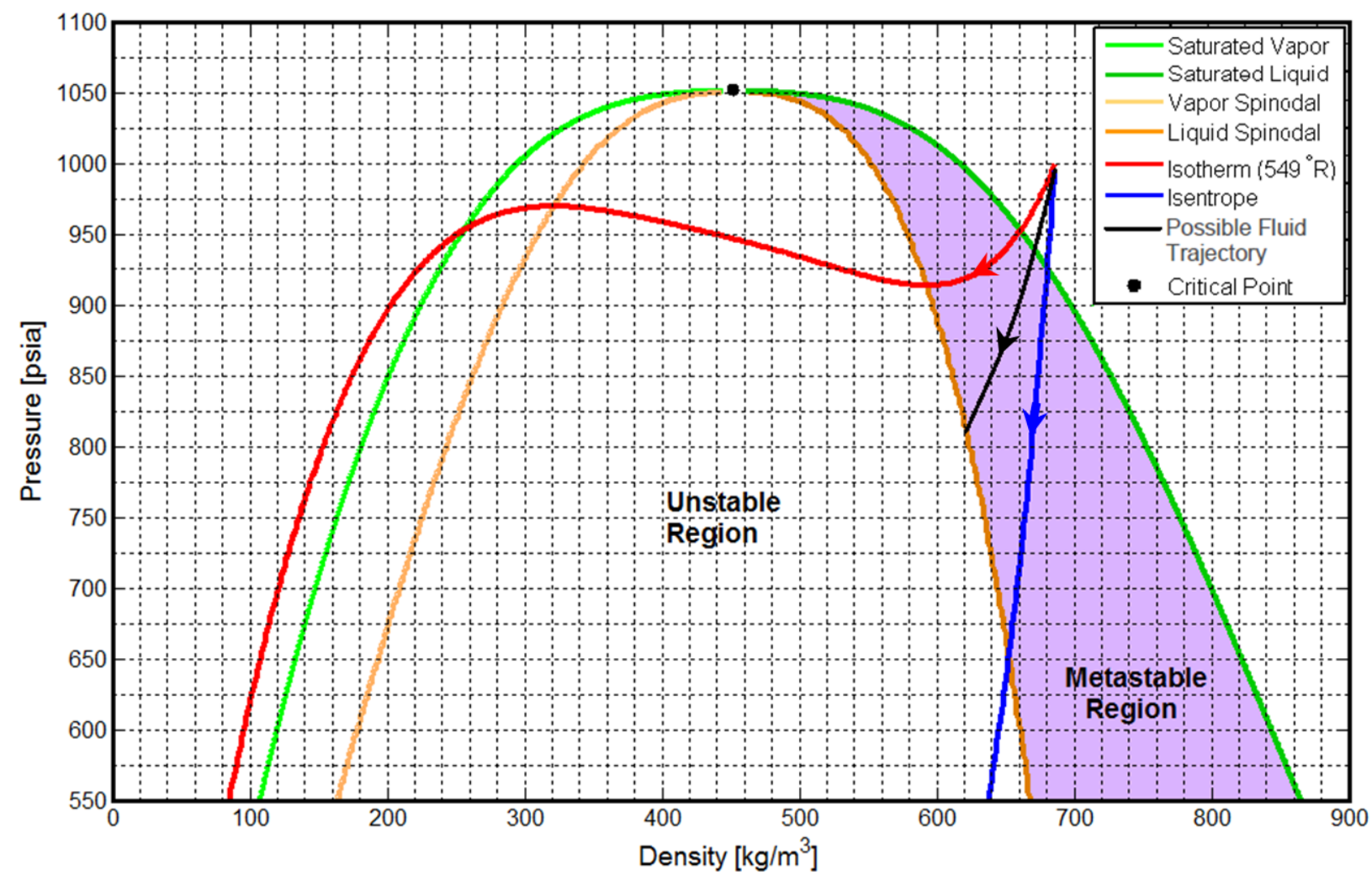

Figure 29. $P-\rho$ Diagram for nitrous oxide. Lines of constant temperature $(305 \mathrm{~K})$ and constant entropy are included for a sub-cooled liquid which starts at 1000 psia and transitions into the metastable region. The data used to produce this plot was calculated using REFPROP $6,76,7$. 